\title{
Aromatic nitrations by mixed acid. Slow liquid-liquid reaction regime
}

\author{
J.M. Zaldívar ${ }^{\mathrm{a}}$, E. Molga ${ }^{\mathrm{b}}$, M.A. Alós ${ }^{\mathrm{a}}$, H. Hernández ${ }^{\mathrm{a}}$, K.R. Westerterp ${ }^{\mathrm{c}}$ \\ aJoint Research Centre of the Commission of the European Communities, Institute for Safety Technology, Process Engineering Division TP680, \\ 21020-Ispra (Va), Italy \\ ${ }^{b}$ Chemical Engineering and Process Department, Warsaw: Technical University, ul. Warynskiego 1, 00645-Warsaw, Poland \\ ${ }^{\circ}$ Chemical Reaction Engineering Laboratories, Department of Chemical Engineering, Twente University of Technology. P.O. Box 217. \\ 7500 AE Enschede. Netherlands
}

Received 2 February 1995; accepted 3 May 1995

\begin{abstract}
Aromatic nitrations by mixed acid have been selected as a specific case of a heterogeneous liquid-liquid reaction. An extensive experimental programme has been followed using adiabatic and heat-flow calorimetry and pilot reactor experiments, supported by chemical analysis. A series of nitration experiments has been carried out to study the influences of different initial and operating conditions such as temperature, stirring speed and sulphuric acid concentration. In parallel, a mathematical model to predict the overall conversion rate has been developed. In this paper the mathematical modelling and the implementation and experimental validation for benzene, toluene and chlorobenzene mononitration in the kinetic control regime (slow liquid-liquid reaction) are presented and discussed.
\end{abstract}

Keywords: Aromatic nitrations; Slow liquid-liquid reactions

\section{Introduction}

Many questions remain to be answered for aromatic nitrations in mixed acid, particularly under the conditions employed in industry, and mainly in discontinuous reactors, despite the fact that nitration was one of the earliest unit processes to be operated on a large scale when the heavy organic chemical industry first developed in the last century. These reactions have played an equally important part in the development of our present understanding of the mechanism of organic reactions, offering a typical example of electrophilic substitution; see the classic investigations of Ingold and co-workers during the 1950 s [1].

The dynamic behaviour of aromatic nitrations by mixed acid in discontinuous reactors involves a considerable number of problems owing to the fact that, in these heterogeneous liquid-liquid reactions, chemical reaction and mass-transfer phenomena occur simultaneously. The occurrence of these phenomena leads to a complex problem when characterizing and scaling-up these processes, owing to the interdependence between fluid properties, operating conditions and equipment characteristics. Furthermore, nitrations involve high exothermicity and side reactions, which, in addition to the previously mentioned phenomena, have produced a considerable number of incidents; see Ref. [2]. Therefore, a better understanding of this kind of process is of great importance for the safe and economic design as well as the optimal operation of nitration plants.

The present investigation was undertaken with the main purpose of studying the dynamic reactor behaviour and the influence of the different initial and operating conditions in discontinuous nitration processes. To achieve this, an extensive experimental programme has been carried out using adiabatic and heat-flow calorimetry and pilot plant experiments, supported by chemical analysis. The adiabatic experiments were performed using a PHI-TEC calorimeter [3] and the isothermal and isoperibolic experiments using an $\mathrm{RCl}$ reaction calorimeter [4], while the pilot plant experiments were carried out in the FIRES facility [5]. Chemical analysis was done by gas chromatography [6].

In parallel, a mathematical model for predicting the overall conversion rate, within the range of experimental conditions studied, has been developed. This model 
has been introduced into the numerical simulator of the $\mathrm{RCl}$ reaction calorimeter [7] in order to compare and validate it with the experimental results. Furthermore, a special version of the simulator is applied on-line to estimate the reaction rate during nitration experiments [8]. These data are compared to those from chemical analysis and simulation.

In this paper two kinetic expressions, based on different acidity functions, are described and implemented to interpret literature data from homogeneous nitration experiments with one liquid phase and low nitric acid concentration, $C_{\mathrm{HNO}_{3}}$ of around $10^{-2} \mathrm{M}$. These kinetic expressions are extended to predict the dynamic behaviour of discontinuous nitrators under industrial conditions with two liquid phases and high nitric acid concentrations $\mathrm{C}_{\mathrm{HNO}_{3}}$ of around $5 \mathrm{M}$. Also they are compared to experimental results from the mononitration of benzene, toluene and chlorobenzene in the kinetic regime of slow liquid-liquid reaction as a first step for the development of an overall conversion rate expression in the mass-transfer control region.

\section{Interpretation of homogeneous kinetic data}

As is well known from literature (Refs. [9,10], among others), the nitration of aromatic compounds by a mixture of nitric and sulphuric acids, called "mixed acid", occurs in the aqueous acid phase (L2), and proceeds through the intermediation of the nitronium ion $\mathrm{NO}_{2}^{+}$:

$\mathrm{NO}_{2}^{+}+\mathrm{ArH} \rightarrow$ products

Hence, if the interaction of the nitronium ion with the aromatic substrate is the rate-limiting step [11], the reaction rate in the acid phase, using a $\mathrm{Br} \varnothing$ nsted-Bjerrum rate law or transition-state theory, can be written as

$r=k_{2}^{\prime} \mathrm{C}_{\mathrm{ArH}}^{\mathrm{L} 2} \mathrm{C}_{\mathrm{NO} \frac{2}{2}}^{\mathrm{LL}} \frac{\gamma_{\mathrm{ArH}_{\mathrm{rH}} \gamma_{\mathrm{NO}_{2}^{+}}}}{\gamma^{\ddagger}}$

Hence, the aromatic compound diffuses through the organic phase to the interface and into the aqueous phase; whilst it is diffusing, it reacts in the boundary layer and/or in the bulk of the aqueous phase with the nitronium ion to form the nitrocompounds, see Fig. 1.

From homogeneous nitration experiments it has been found, among others by Deno and Stein [12] and Coombes et al. [13], that second-order kinetics hold, and rate coefficients were determined related to stoichiometric concentrations of reagents as

$r=k_{2} \mathrm{C}_{\mathrm{HNO}} \mathrm{L}_{3} \mathrm{C}_{\mathrm{ArH}}^{\mathrm{L} 2}$

Plots of the observed rate constant, $k_{2}$, vs. sulphuric acid composition, see benzene in Fig. 2, show that $k_{2}$ is a strong function of the sulphuric acid strength, and

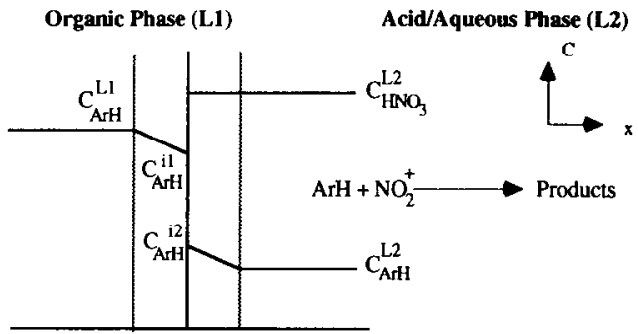

Fig. 1. Schematic representation of mass transfer with chemical reaction during the nitration of an aromatic compound, according to the stagnant-film theory. Concentration profiles near the liquid-liquid interface for a slow reaction and low solubility.

that the observed second-order rate of Eq. (3) changes by many orders of magnitude as the weight percentage of sulphuric acid changes: for example, $k_{2}$ increases typically by a factor of $10^{9}-10^{12}$ between 50 and 80 wt. $\% \mathrm{H}_{2} \mathrm{SO}_{4}$. Furthermore, it has long been noted that the rates of nitration of different compounds unexpectedly showed a maximum at approximately $90 \mathrm{wt} \%$ $\mathrm{H}_{2} \mathrm{SO}_{4}$ and then a gentle decrease in the $90-98$ wt. \% $\mathrm{H}_{2} \mathrm{SO}_{4}$ range; see nitrobenzene in Fig. 2.

In order to obtain the reaction rate constant $k_{2}^{\prime}$ by comparing Eqs. (2) and (3), and to explain the dependence of nitration rates on the sulphuric acid concentration, it is necessary to know the mechanism of the formation of $\mathrm{NO}_{2}^{+}$. Correlations of nitration rates with different acidity functions $H_{0}, H_{\mathrm{R}}$ and $M_{\mathrm{c}}$ have been used to get information on the reaction mechanism as well as acidity dependence of reagents $[9,16]$. In this paper, two of these kinetic formulations will be developed from homogeneous nitration data and then used to predict the reaction rate constants under industrial conditions.

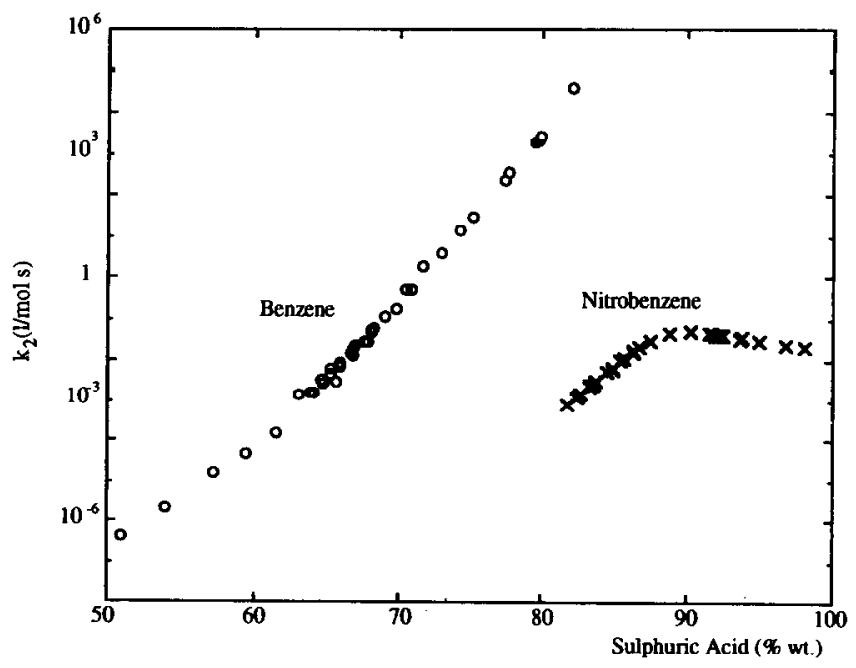

Fig. 2. Observed second-order rate constants for the nitration of benzene and nitrobenzene in sulphuric acid at $298.2 \mathrm{~K}$. Experimental data from Refs. [12-15]. 


\subsection{Determination of $k_{2}^{\prime}$ using the $H_{R}$ acidity function}

Field and Strachan [17] described the formation mechanism of the nitronium ion as

$\mathrm{HNO}_{3} \cdot \mathrm{H}_{2} \mathrm{O}+\mathrm{HA} \stackrel{K}{\rightleftarrows} \mathrm{NO}_{2}^{+}+2 \mathrm{H}_{2} \mathrm{O}+\mathrm{A}^{--}$

HA being any strong acid, in this case sulphuric or nitric acid. Eq. (4) takes into account the experimental fact that two water molecules are needed to hydrate the nitronium ion [18]. The role of the second water molecule in the hydration step is that of a general-base catalyst.

The equilibrium constant $K$ in Eq. (4) is expressed as:

$K=\frac{a_{\mathrm{NO}_{2}}^{+} a_{\mathrm{H}_{2} \mathrm{O}}^{2} a_{\mathrm{A}-}}{a_{\mathrm{HNO}_{3} \cdot \mathrm{H}_{2} \mathrm{O}} a_{\mathrm{HA}}}$

For the acid compositions employed in industrial mononitrations, the concentration of the nitronium ion is so small that the activity of the nitronium ion equals its concentration. Hence

$C_{\mathrm{NO}_{2}}^{+} \approx a_{\mathrm{NO}_{2}}^{+}=\frac{K C_{\mathrm{HNO}_{3} \cdot \mathrm{H}_{2} \mathrm{O}_{2}}^{\mathrm{L}} \gamma_{\mathrm{HNO}_{3} \cdot \mathrm{H}_{2} \mathrm{O}} a_{\mathrm{HA}}}{a_{\mathrm{H}_{2} \mathrm{O}}^{2} a_{\mathrm{A}}-}$

Furthermore, if we assume the concentration of the aromatic species in the acid phase to be small, the activity coefficients are equal to one, and it is possible to obtain

$k_{2}=\frac{r}{C_{\mathrm{HNO}{ }_{3}}^{\mathrm{L} 2} C_{\mathrm{ArH}}^{\mathrm{L} 2}}=k_{2}^{\prime} K_{\gamma_{\mathrm{HNO}}}^{\prime} \cdot \mathrm{H}_{2} \mathrm{O} \frac{a_{\mathrm{HA}}}{a_{\mathrm{H}_{2} \mathrm{O}}^{2} a_{\mathrm{A}}-}$

by introducing Eq. (6) into Eq. (2) and comparing this with Eq. (3). If we now take logarithms, we will obtain

$\log k_{2}=\log k_{2}^{\prime}+\log K+\log \gamma_{\mathrm{HNO}_{3} \cdot \mathrm{H}_{2} \mathrm{O}}+\log \frac{a_{\mathrm{HA}}}{a_{\mathrm{H}_{2} \mathrm{O}}^{2} a_{\mathrm{A}}-}$

The following also holds:

$\log \frac{a_{\mathrm{HA}}}{a_{\mathrm{H}_{2} \mathrm{O}}^{2} a_{\mathrm{A}}}=-\left(H_{\mathrm{R}}+\log a_{\mathrm{H}_{2} \mathrm{O}}\right)$

where $H_{\mathrm{R}}$ is the acidity function [19]. Hence

$\log k_{2}=\log k_{2}^{\prime}+\log K+\log \gamma_{\mathrm{HNO}_{3} \cdot \mathrm{H}_{2} \mathrm{O}}$

$$
-\left(H_{\mathrm{R}}+\log a_{\mathrm{H}_{2} \mathrm{O}}\right)
$$

In the homogeneous nitration experiments - the concentration of nitric acid is low - the activity coefficient, assuming infinite dilution as standard state, can be approximated as equal to one; hence the plot of $\log k_{2}$ vs. $-\left(H_{\mathrm{R}}+\log a_{\mathrm{H}_{2} \mathrm{O}}\right)$ should give a straight line with a slope of 1 and intercept $\log \left(k_{2}^{\prime} K\right)$ [20].

Consequently, to obtain $k_{2}^{\prime}$ from homogeneous nitration rate experiments, it is necessary to calculate:

(a) The acidity function, $H_{R}$. The direct determination of the nitronium ion concentration is not possible for the mixed acid commonly used for mononitrations. To

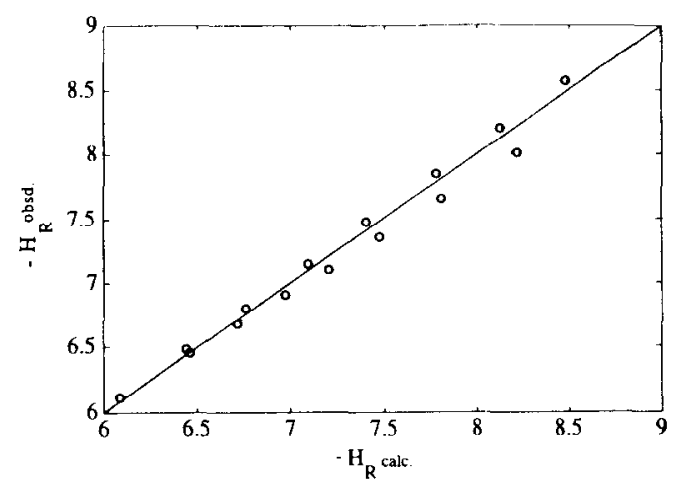

Fig. 3. Parity plot of $H_{\mathrm{R}}$ values measured by Kanhere and Chandalia [23] and calculated according to Eq. (15), for different mixed-acid compositions at $308.2 \mathrm{~K}$.

overcome this problem, the similarity of behaviour of triarylcarbinols $(\mathrm{ROH})$ or their derivates in sulphuric acid with that of nitric acid has been extensively used:

$\mathrm{ROH}+\mathrm{HA} \rightleftarrows \mathrm{R}^{+}+\mathrm{I}_{2} \mathrm{O}+\mathrm{A}^{-}$
$\mathrm{HNO}_{3}+\mathrm{HA} \rightleftarrows \mathrm{NO}_{2}^{+}+\mathrm{H}_{2} \mathrm{O}+\mathrm{A}$

The measurement of the ionization ratios $C_{\mathrm{R}}+C_{\mathrm{ROH}}$ by indicators undergoing ionization according to $\mathrm{Eq}$. (11) has become the basis of an acidity function [21] defined as

$H_{\mathrm{R}}=-p K_{\mathrm{ROH}}-\log \frac{C_{\mathrm{R}}}{C_{\mathrm{ROH}}}$

Rearrangement of Eq. (13) leads to:

$H_{\mathrm{R}}=-\log \frac{a_{\mathrm{HA}}}{a_{\mathrm{H}_{2} \mathrm{O}} a_{\mathrm{A}}-}$

It follows that $H_{\mathrm{R}}$ approaches the $\mathrm{pH}$ at low ionic strengths and becomes identical at infinite dilution.

Experimental data from Cook et al. [22] showed $H_{\mathrm{R}}$ to be proportional to $1 / T$, whereas Kanhere and Chandalia [23] correlated $H_{\mathrm{R}}$ to be a linear function of the sulphuric acid and nitric acid concentrations. Following those studies, the acidity function has been correlated by us as:

$$
\begin{aligned}
H_{\mathrm{R}}= & -\left(5.046 C_{\mathrm{H}_{2} \mathrm{SO}_{4}}+3.268 C_{\mathrm{HNO}_{3}}\right) \\
& \times\left(-0.214+\frac{124.65}{T}\right)
\end{aligned}
$$

In Fig. 3 the comparison between the experimental and correlated data for different mixed-acid compositions is shown, whereas in Fig. 4 the temperature dependence is illustrated.

(b) Activity coefficients for the mixed acid. The multicomponent Wilson equation, using optimum binary Wilson parameters, was applied to predict the activity coefficients; see Appendix 1. 
(c) The equilibrium constant $K$ for the formation of the nitronium ion. In the nitration of 1-3-bis(trifluoromethyl)benzene, Miller et al. [24] found a certain value for $K$ at $298.2 \mathrm{~K}$. Using this value, the free energy was obtained, being $\Delta G=45.37 \mathrm{~kJ} \mathrm{~mol}^{-1}$ [25]. However, it is well known that the linear relationship between $\log k_{2}$ and $\left(H_{\mathrm{R}}+\log a_{\mathrm{H}_{2} \mathrm{O}}\right)$ fails if wide acidity ranges are examined; for example, for halogenobenzenes when a range of $54-77 \mathrm{wt} . \% \mathrm{H}_{2} \mathrm{SO}_{4}$ is considered [14]. To overcome this problem, and as $k_{2}^{\prime}$ should be the true rate constant and not a function of the composition of the medium, $\Delta G$ was assumed to be a function of the sulphuric acid strength, and independent of the aromatic compound being nitrated. With these assumptions, it was possible to obtain - by a non-linear least-squares optimization of more than 20 different compounds with $x=45-82 \%$ and at different temperatures - the following empirical correlation for the free energy

$\Delta G=1.9188 \times 10^{4}+9.85014 \times 10^{2} x-10.5177 x^{2}$

where $x$ is the sulphuric acid strength, expressed as weight percentage of sulphuric acid in the total mass of sulphuric acid plus water; $x$ approximately equals the weight percent of sulphuric acid in the case of homogeneous nitration experiments. The starting values for the correlation were the data from Miller et al. [24]. In this case, as $K$ is not an experimental value, it is not possible to establish whether the "true" value of $K$ or $c K$ and $c^{-1} k_{2}^{\prime}$ have been found, but for the purposes of this work this is not important, since they will be always used as a product in Eq. (10).

Figs. 5 to 7 show the comparison between experimental and calculated values for $k_{2}$ at $298.2 \mathrm{~K}$ as a function of the sulphuric acid strength. It can be seen that at low and medium sulphuric acid concentrations up to $85 \%$,

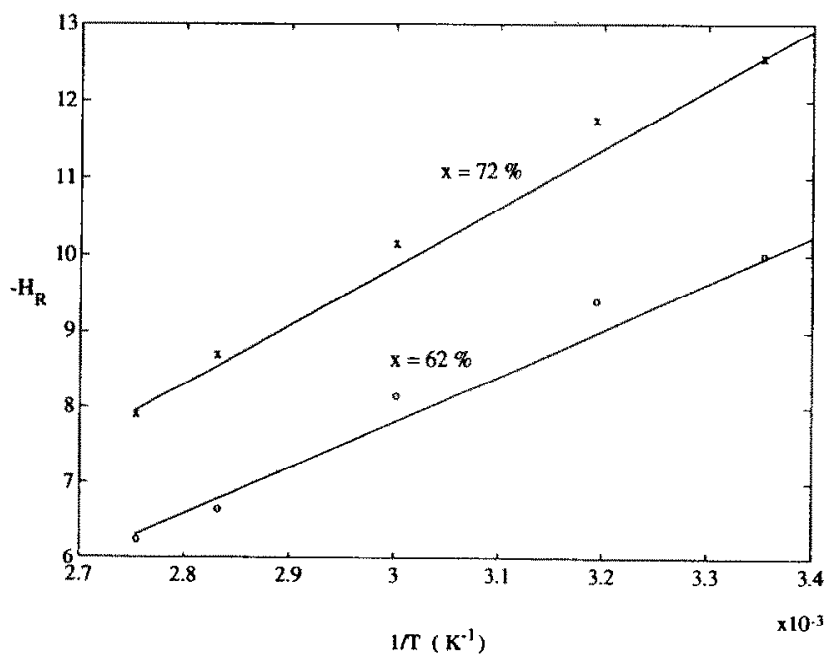

Fig. 4. $-H_{\mathbf{R}}$ values measured by Cook et al. [22] and correlation curves according to Eq. (15) for sulphuric acid of $62(0)$ and $72(x)$ wt. $\%$ as a function of the inverse of temperature.
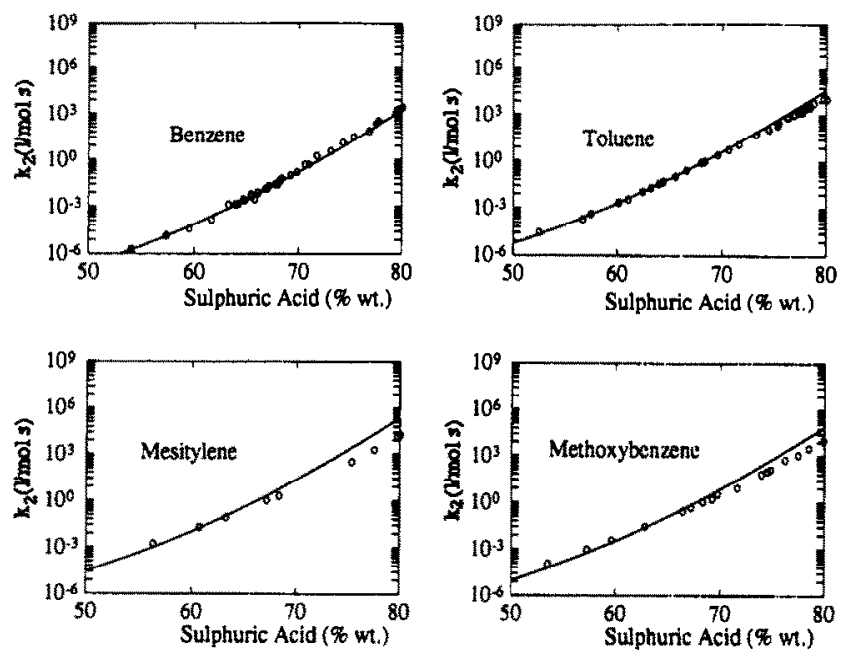

Fig. 5. Experimental $(O)$ and calculated (line) second-order nitration rate constants for benzene, toluene, mesitylene and methoxybenzene at $298.2 \mathrm{~K}$. Experimental data from Refs. $[12,13,18,26,27]$. Calculation with Eq. (10).

Eq. (10) produces accurate results. At high sulphuric acid concentrations (see Fig. 7) the results are poor. Different explanations have been proposed in the literature for this behaviour [9], amongst them that at these concentrations the activity coefficient of nitronium ion can no longer be equated to the concentration, see Eq. (6), and that to interpret the experimental results correctly, activity functions instead of concentrations should be introduced in the kinetic formulations.

Using the previous empirical correlations and experimental data from homogeneous nitration experiments at different temperatures, it is possible to obtain $k_{2}^{\prime}$ for each aromatic compound. The frequency factor and the activation energy are given in Table 1 for some aromatic compounds; see Appendix 2 for the derivation.
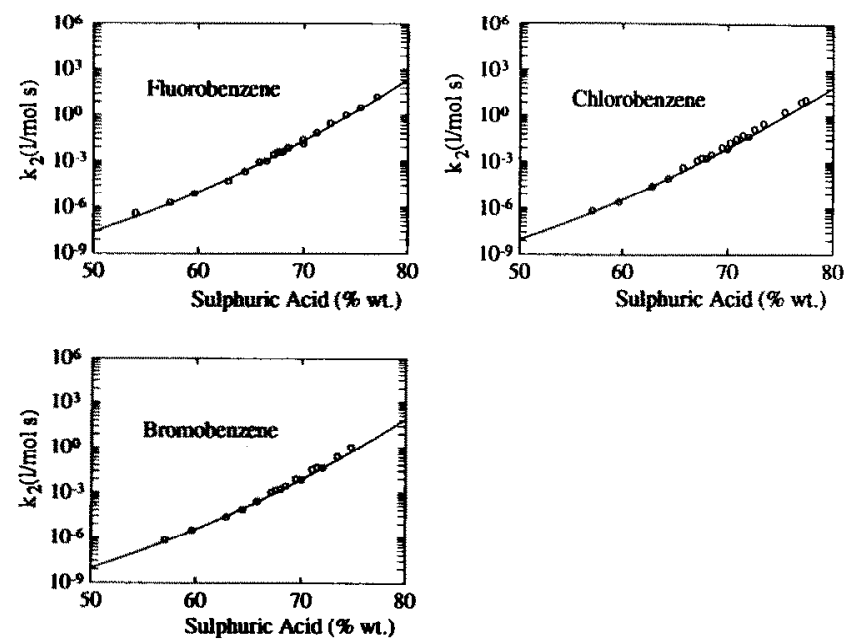

Fig. 6. Experimental $(O)$ vs. calculated (line) second-order nitration rate constants for halogenobenzenes at $298.2 \mathrm{~K}$. Experimental data from Refs. [12,14,28]. Calculation with Eq. (10). 

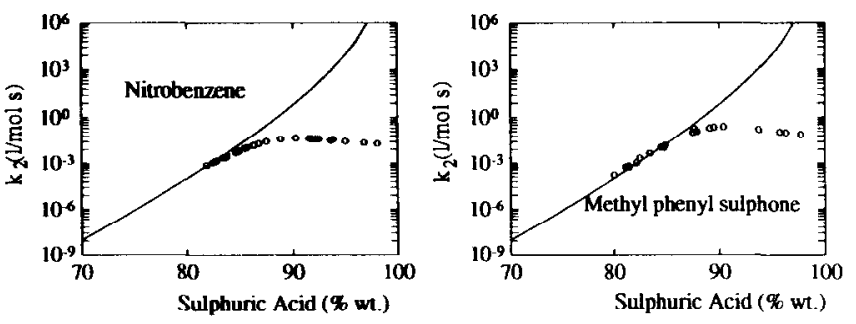

Fig. 7. Experimental ( $O$ ) vs. calculated (line) second-order nitration rate constants for nitrobenzene and methyl phenyl sulphone at 298.2 K. Experimental data from Marziano et al. [15]. Calculation with Eq. (10).

\subsection{Determination of $k_{2}^{\prime}$ using the $M_{c}$ activity coefficient function}

To solve the problems and shortcomings of the above formulation, Marziano and co-workers [14-16] developed a new method to describe the second-order nitration rates observed in homogeneous experiments. This method takes into account the effective concentration of solutes and changes in the $\gamma_{\mathrm{ArH}} \gamma_{\mathrm{NO}_{2}+} / \gamma^{\ddagger}$ ratio with acidity, using the $M_{\mathrm{c}}$ function to be discussed in the following. With this procedure, they were able to obtain a correct description of rate profiles for acid concentrations below and above $90 \mathrm{wt} \%$ of sulphuric acid.

It is well known that two different equilibria for nitric acid coexist simultaneously in aqueous sulphuric acid, i.e.

$\mathrm{HNO}_{3} \rightleftarrows \mathrm{H}^{+}+\mathrm{NO}_{3}^{-}$

$\mathrm{HNO}_{3}+\mathrm{H}^{+} \rightleftarrows \mathrm{NO}_{2}^{+}+\mathrm{H}_{2} \mathrm{O}$

The corresponding equilibrium constants can be written as

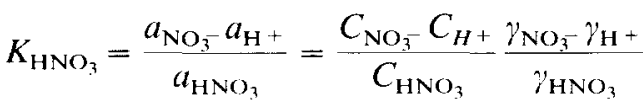

for the nitric acid dissociation and

$K_{\mathrm{NO}_{2}^{+}}=\frac{a_{\mathrm{HNO}_{3}} a_{\mathrm{H}^{+}}}{a_{\mathrm{NO}_{2}+} a_{\mathrm{H}_{2} \mathrm{O}}}=\frac{C_{\mathrm{HNO}_{3}} C_{H^{+}}}{C_{\mathrm{NO}_{2}+} C_{\mathrm{H}_{2} \mathrm{O}}} \frac{\gamma_{\mathrm{HNO}_{3}} \gamma_{\mathrm{H}}+}{\gamma_{\mathrm{NO}_{2}} \gamma_{\mathrm{H}_{2} \mathrm{O}}}$

for the inverse of the nitronium ion formation. The equilibria of Eqs. (17) and (18) have been experimentally studied using various spectroscopic techniques, amongst others Raman and UV spectroscopy [29-31] and ${ }^{14} \mathrm{~N}$ NMR [32] in a wide acidity range from 1 to 98

Table 1

Frequency factor and activation energy for the reaction rate constant $k_{2}^{\prime}$

\begin{tabular}{lcc}
\hline Compound & $\ln A$ & $E_{\mathrm{a} /} / R \times 10^{-3}$ \\
\hline Benzene & 51.456 & 2.03 \\
Toluene & 62.362 & 22.83 \\
Chlorobenzene & 59.451 & 23.16 \\
\hline
\end{tabular}

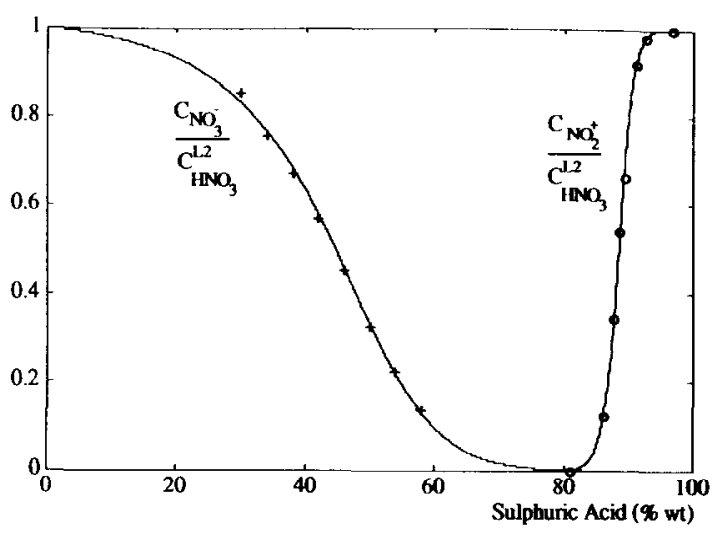

Fig. 8. Experimental vs. with Eqs. (23) and (24) calculated fractional conversion of nitric acid in sulphuric acid of varying strength at 298.2 K. Experimental data from Deno et al. [29] $(+)$; and Ross et al. [32] (O).

wt.\% sulphuric acid. From these experiments the evaluated values at $298.2 \mathrm{~K}$ were $K_{\mathrm{HNO}_{3}}=284.75$ and $K_{\mathrm{NO}_{2}^{+}}=1.47523 \times 10^{1 /}[33]$.

Fig. 8 shows how the equilibria switch from the nitric acid dissociation to the nitronium ion formation as the sulphuric acid weight percent increases. The point of a $50 \%$ formation of nitronium ion at $298.2 \mathrm{~K}$ occurs at about 88 wt. $\% \mathrm{H}_{2} \mathrm{SO}_{4}$, and at acidities greater than 93 wt. $\% \mathrm{H}_{2} \mathrm{SO}_{4}$ the nitronium ion is practically the only species.

Following the work of Marziano and co-workers, it is possible to use the empirical activity coefficient or $M_{\mathrm{c}}$ function [34,35], also called the excess acidity function, defined formally as

$$
M_{\mathrm{c}}-\log \frac{\prod \text { activity coefficients of reactants }}{\prod \text { activity coefficients of products }}
$$

to evaluate Eqs. (19) and (20). The $M_{\mathrm{c}}$ procedure is based on the following empirical linear relationship in concentrated acid solutions for the protonation equilibria of two generic basic indicators, $i$ and $j$

$$
-\log \left(\frac{\gamma_{\mathrm{B}_{i}} \gamma_{\mathrm{A}_{i}}}{\gamma_{\mathrm{C}_{i}}}\right)=-n_{i j} \log \left(\frac{\gamma_{\mathrm{B}_{i} \gamma_{\mathrm{A}_{i}}}}{\gamma_{\mathrm{C}_{j}}}\right)
$$

where $\mathrm{B}$ is base, $\mathrm{A}$ acid, $\mathrm{C}$ conjugated acid and $n_{i j}$ a constant dependent on the two indicators. This empirical equation shows that the ratio of activity coeficients of base $i$ are multiples of those of base $j$. Therefore, substituting Eq. (21) into Eqs. (19) and (20) and using the values obtained by Sampoli et al. [36] for $n_{\mathrm{HNO}_{3}}$ and $n_{\mathrm{NO}_{2}+}$, the equations read

$$
\begin{gathered}
K_{\mathrm{HNO}_{3}}=\frac{C_{\mathrm{NO}_{3}^{-}} C_{\mathrm{H}+}}{C_{\mathrm{HNO}_{3}}} 10^{-0.571 M_{\mathrm{c}}} \\
K_{\mathrm{NO}_{2}^{+}}=\frac{C_{\mathrm{HNO}_{3}} C_{\mathrm{H}^{+}}}{C_{\mathrm{NO}_{2}+} C_{\mathrm{H}_{2} \mathrm{O}}} 10^{-2.542 M_{\mathrm{c}}}
\end{gathered}
$$


Furthermore, combining Eq. (2) and Eq. (3) yields

$k_{2}^{\prime} C_{\mathrm{NO}_{2}^{+}}^{\mathrm{L2}} \frac{\gamma_{\mathrm{ArH}^{2}} \gamma_{\mathrm{NO}_{2}}}{\gamma^{\ddagger}}=k_{2} C_{\mathrm{HNO}_{3}}^{\mathrm{L} 2}$

and assuming the $M_{\mathrm{c}}$ function is also able to describe the ratio of the activity coefficients of the nitration rate process [15], we obtain

$k_{2}^{\prime} C_{\mathrm{NO}_{2}+}^{\mathrm{L} 2} 10^{-n M_{\mathrm{c}}}=k_{2} C_{\mathrm{HNO}_{3}}^{\mathrm{L} 2}$

As the total concentration of nitric acid $\mathrm{C}_{\mathrm{HNO}_{3}}^{\mathrm{L} 2}$ can be expressed as

$C_{\mathrm{HNO}_{3}}^{\mathrm{L} 2}=C_{\mathrm{NO}_{3-}^{-}}+C_{\mathrm{HNO}_{3}}+C_{\mathrm{NO}_{2}^{+}}$

Eq. (22) leads to

$k_{2}^{\prime} 10^{-n M_{\mathrm{c}}}=k_{2}\left(\frac{C_{\mathrm{NO}_{3}}}{C_{\mathrm{NO}_{2}^{+}}}+\frac{C_{\mathrm{HNO}_{3}}}{C_{\mathrm{NO}_{2}^{+}}}+1\right)$

Using Eq. (24) and Eq. (25), it is possible to obtain:

$$
\begin{aligned}
k_{2}^{\prime} 10^{-n M_{\mathrm{c}}}= & k_{2}\left(\frac{K_{\mathrm{HNO}_{3}}}{C_{\mathrm{H}^{+}} 10^{-0.571 M_{\mathrm{c}}}}+1+\frac{C_{\mathrm{H}^{+}} 10^{-2.542 M_{\mathrm{c}}}}{C_{\mathrm{H}_{2} \mathrm{O}} K_{\mathrm{NO}_{2}{ }^{+}}}\right) \\
& \times \frac{C_{\mathrm{H}_{2} \mathrm{O}} K_{\mathrm{NO}_{2}^{+}}}{C_{\mathrm{H}^{+}} 10^{-2.542 M_{\mathrm{c}}}}
\end{aligned}
$$

In consequence, plotting the logarithm of the righthand side of Eq. (28) vs. $M_{\mathrm{c}}$ should give a straight line with a slope equal to $n$ and an intercept equal to $k_{2}^{\prime}$ [15]. Hence, in order to obtain the values of $k_{2}^{\prime}$ and $n$, which will be specific for each aromatic compound, it is necessary to calculate:

(a) The $M_{c}$ function. The $M_{\mathrm{c}}$ function at $298.2 \mathrm{~K}$ was correlated by Marziano et al. [35] as a polynomial expansion:

$$
\begin{aligned}
-M_{\mathrm{c}}= & 0.2264 C_{\mathrm{H}_{2} \mathrm{SO}_{4}}+0.0216 C_{\mathrm{H}_{2} \mathrm{SO}_{4}}^{2} \\
& -0.1394 \times 10^{-2} C_{\mathrm{H}_{2} \mathrm{SO}_{4}} \\
& +0.2134 \times 10^{-3} C_{\mathrm{H}_{2} \mathrm{SO}_{4}} \\
& -0.4274 \times 10^{-4} C_{\mathrm{H}_{2} \mathrm{SO}_{4}}^{5} \\
& +0.3078 \times 10^{-5} C_{\mathrm{H}_{2} \mathrm{SO}_{4}}^{6} \\
& +0.6355 \times 10^{-7} C_{\mathrm{H}_{2}}^{7} \mathrm{SO}_{4} \\
& 0.1434 \times 10^{-7} C_{\mathrm{H}_{2}}^{8} \mathrm{SO}_{4} \\
& +0.3930 \times 10^{-9} C_{\mathrm{H}_{2} \mathrm{SO}_{4}}^{9}
\end{aligned}
$$

This function can, in principle, be extended to temperatures other than $298.2 \mathrm{~K}$, according to Cox et al. [37], by

$M_{\mathrm{c}}(T)=\frac{298.2 M_{\mathrm{c}}(298.2)}{T}$

(b) The proton concentration. The experimental data from Robertson and Dunford [38] for the proton concentration in aqueous sulphuric acid in the range of 1 to $99 \mathrm{wt} . \%$ and at $298.2 \mathrm{~K}$ were correlated according to the following function

$$
\begin{aligned}
C_{\mathrm{H}^{+}}= & -1.1757 \times 10^{-2}+1.2406 C_{\mathrm{H}_{2} \mathrm{SO}_{4}} \\
& +9.4286 \times 10^{-2} C_{\mathrm{H}_{2} \mathrm{SO}_{4}}^{2}-2.5102 \times 10^{-2} C_{\mathrm{H}_{2}}^{3} \mathrm{SO}_{4} \\
& +2.171 \times 10^{-3} C_{\mathrm{H}_{2} \mathrm{SO}_{4}}^{4} \\
& -6.917 \times 10^{-5} C_{\mathrm{H}_{2} \mathrm{SO}_{4}}
\end{aligned}
$$

Furthermore it was assumed, as a first approximation, that this proton concentration would not change appreciably with temperature [39].

(c) The equilibrium constants $K_{\mathrm{NO}_{2}}$ and $\mathrm{K}_{\mathrm{HNO}_{3}}$ as a function of temperature. It has been assumed for the nitric acid dissociation that

$K_{\mathrm{INO}_{3}}=\exp \left(-\frac{\Delta G_{\mathrm{HNO}_{3}}}{R T}\right)$

where $\Delta G_{\mathrm{HNO}_{2}}$ was calculated from data at $298.2 \mathrm{~K}$. Ross et al. [22], using ${ }^{14} \mathrm{~N}$ NMR, studied the equilibrium Eq. (18) for temperatures between 287.36 and $316.16 \mathrm{~K}$. Using their data, it was possible to correlate the formation of the nitronium ion constant $K_{\mathrm{NO}_{2}}$ as

$K_{\mathrm{NO}_{2}^{+}}=\exp \left(\frac{1.360 \times 10^{4}}{T}-5.935\right)$

Figs. 9-11 show the comparison between predicted and calculated values for $\log k_{2}$ at $298.2 \mathrm{~K}$ as a function of sulphuric acid strength. These figures show that the correlation for calculating the observed second-order rate constants produces accurate results, even at high sulphuric acid concentrations, i.e. in the case for nitrobenzene and methyl phenyl sulphone.

Using the empirical correlations obtained above and experimental data from homogeneous nitration experiments at different temperatures, it is possible to obtain
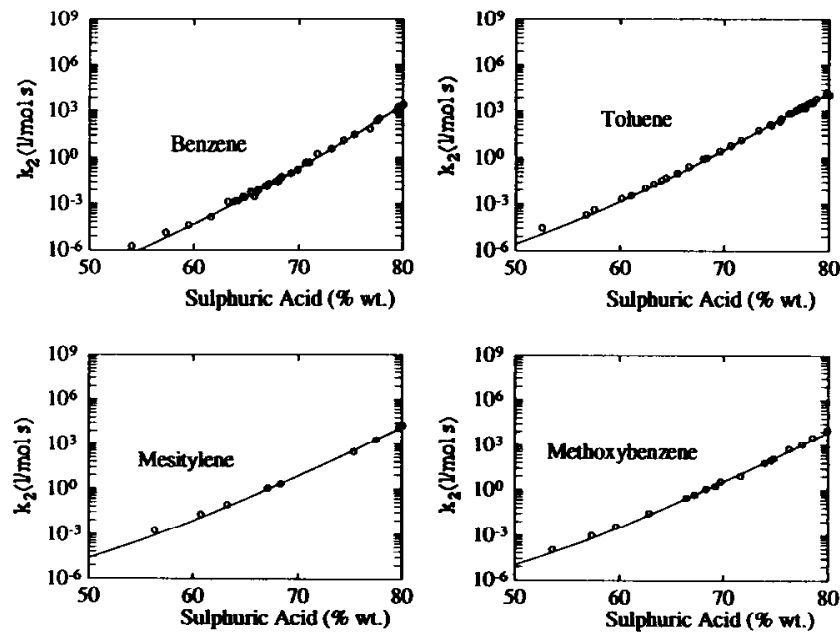

Fig. 9. Experimental $(O)$ vs. calculated (line) second-order nitration rate constants for benzene, toluene, mesitylene and methoxybenzene at $298.2 \mathrm{~K}$, using Eq. (28). 

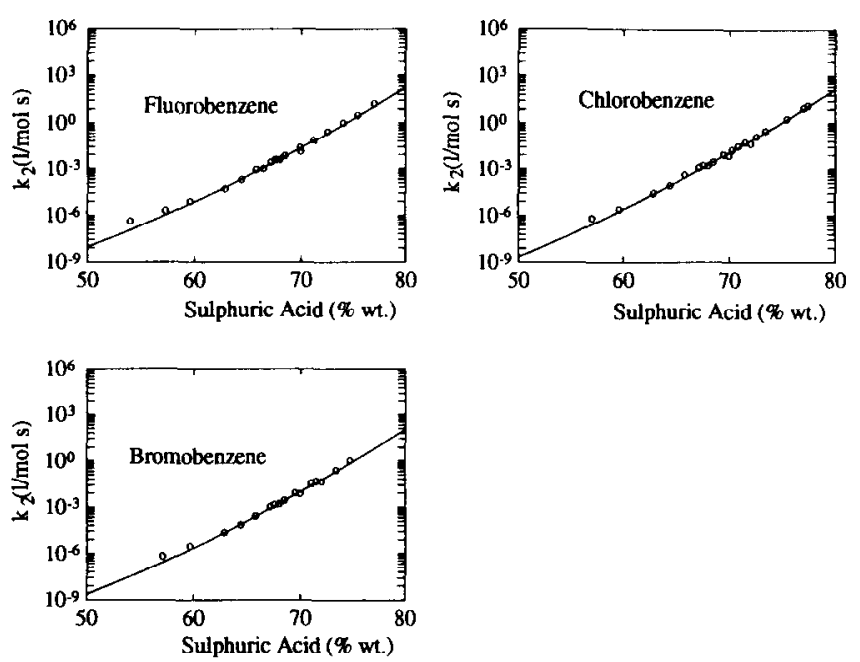

Fig. 10. Experimental $(O)$ vs. calculated (line) second-order nitration rate constants for halogenobenzenes at $298.2 \mathrm{~K}$, using Eq. (28).

$k_{2}^{\prime}$ for each aromatic compound. The frequency factor and the activation energy are given in Table 2 for different aromatic compounds; see Appendix 3 for the derivation.

\section{Solubility of aromatic compounds in mixed acid: measurement and prediction}

An important parameter in the derivation of an overall reaction rate expression is the solubility of the aromatic compounds in mixed acid, since it determines the maximum possible concentration in the reaction phase. Cerfontain [40] showed that the solubility of aromatic compounds in aqueous sulphuric acid can be correlated by

$m_{\mathrm{ArH}}=\frac{C_{\mathrm{ArH}}^{\mathrm{L} 2}}{C_{\mathrm{ArH}}^{\mathrm{L} 1}}=\exp \left(-\frac{\Delta G_{\mathrm{ArH}}}{R T}\right)$

where $\Delta G_{\mathrm{ArH}}$ is a function of the sulphuric acid strength, the difference in internal pressure of the two immiscible solvents and the molar volume of the aromatic compound. It was found by Ismail [41] that in industrial mixed acids the effect of the nitric acid concentration on the total solubility also has to be taken
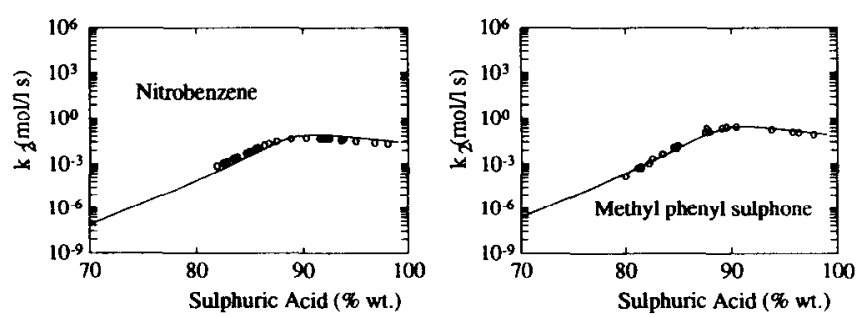

Fig. 11. Experimental (O) vs. calculated (line) second-order nitration rate constants for nitrobenzene and methyl phenyl sulphone at 298.2 $\mathrm{K}$, using Eq. (28).
Table 2

Frequency factor and activation energy, for the reaction rate constant $k_{2}^{\prime}$, and $n$

\begin{tabular}{llll}
\hline Compound & $\ln A$ & $E_{\mathrm{a}} / R \times 10^{-3}$ & $n$ \\
\hline Benzene & 25.074 & 4.033 & 0.318 \\
Toluene & 32.264 & 4.989 & 0.140 \\
Chlorobenzene & 28.852 & 6.003 & 0.389 \\
\hline
\end{tabular}

into account. Therefore, following the work of Cerfontain, $\Delta G_{\mathrm{ArH}}$ was empirically correlated as

$\Delta G_{\mathrm{ArH}}=c_{1} f\left(x_{\mathrm{S}}\right) f\left(x_{\mathrm{N}}\right)+c_{2}-c_{3} T$

where $c_{1}, c_{2}$ and $c_{3}$ are constants, to be determined for each individual aromatic compound, and $f\left(x_{\mathrm{S}}\right)$ and $f\left(x_{\mathrm{N}}\right)$ are polynomial functions of the sulphuric acid and nitric acid molar fractions, respectively.

$f\left(x_{\mathbf{S}}\right)=\sum_{i} d_{i} x_{\mathbf{S}}^{i-1}$

$f\left(x_{\mathrm{N}}\right)=\sum_{i} b_{i} x_{\mathrm{N}}^{i-1}$

The constants of Eq. (35) for benzene, toluene and chlorobenzene are given in Table 3 , whereas the coefficients of the polynomials $f\left(x_{\mathrm{S}}\right)$ and $f\left(x_{\mathrm{N}}\right)$, Eqs. (36) and (37), are given in Tables 4 and 5. Fig. 12 shows a comparison between experimental and calculated distribution coefficients for chlorobenzene at $298.2 \mathrm{~K}$ in aqueous sulphuric acid. It can be seen that benzene, toluene and chlorobenzene have very low distribution coefficients of $(2-4) \times 10^{-4}$ in the range of interest for mononitration between 60 and $80 \mathrm{wt} . \% \mathrm{H}_{2} \mathrm{SO}_{4}$; this will simplify the derivation of the overall rate expression.

In order to take into account the amount of nitric acid present in the organic phase, and therefore not available to form nitronium ion, experimental data from Refs. [41,45-47] were used to derive a similar expression to Eq. (35), also accounting for the amount of conversion in the organic phase.

\section{Overall conversion rates for slow liquid-liquid reactions}

It is well known that, in heterogeneous liquid-liquid reactions, mass transport can be increased if the sub-

Table 3

Constants for the calculation of the distribution coefficient of aromatic compounds. Experimental data from Refs. [40]-[44]

\begin{tabular}{llrr}
\hline Compound & $c_{1}$ & $c_{2} \times 10^{3}$ & \multicolumn{1}{c}{$c_{3}$} \\
\hline Benzene & 57.087 & -1.382 & -5.198 \\
Toluene & 44.359 & 14.576 & 28.638 \\
Chlorobenzene & 41.788 & 4.170 & -15.414 \\
\hline
\end{tabular}


Table 4

Constants for the calculation of Eq. (36)

\begin{tabular}{lllrrrrr}
\hline Compound & $d_{1}$ & $d_{2}$ & $d_{3} \times 10^{-2}$ & $d_{4} \times 10^{-3}$ & $d_{5} \times 10^{-5}$ & $d_{6} \times 10^{-7}$ & $d_{7} \times 10^{-9}$ \\
\hline Benzene & 167.001 & 6.0582 & -44.556 & 13.4011 & -13.821 & -5.9687 & 12.8762 \\
Toluene & 172.399 & 3.4795 & -8.7417 & 0.1209 & 0.1658 & 3.9341 & -6.4481 \\
Chlorobenzene & 171.868 & 3.1632 & -9.5261 & -0.9216 & 2.6910 & 4.5063 & -7.6594 \\
\hline
\end{tabular}

stance transported into the other phase reacts there chemically. Vice versa, chemical reaction can be slowed down by a mass-transfer resistance, so that the conversion rate is lower than the chemical reaction rate. If the rate of chemical reaction is slow with respect to the rate of mass transfer, the rate of mass transfer is not enhanced by reaction, and the reaction mainly proceeds in the bulk of the reaction phase. For such situations, we must check that the consumption by reaction in the thin boundary layer is negligible. This assumption is justified if IIa $<0.3$ holds; see Westerterp et al. [48], where the Hatta number $\mathrm{Ha}$ is defined as

$\mathrm{Ha}=\frac{\sqrt{k_{2} D_{\mathrm{ArH}_{\mathrm{H}} C_{\mathrm{HNO}}}^{\mathrm{L} 2}}}{k_{\mathrm{L} 2}}$

and $D_{\mathrm{ArH}}$ is the diffusivity of the aromatic compound in the acid phase.

Furthermore, as the solubility of the aromatic compounds in the acid phase is low and the mass transfer coefficients $k_{\mathrm{L} 1}$ and $k_{\mathrm{L} 2}$ being of the same order of magnitude, also $k_{\mathrm{L} 1} / k_{\mathrm{L} 2} m \gg 1$, so it can be assumed that $C_{\mathrm{ArH}}^{i 1} \approx C_{\mathrm{ArH}}^{\mathrm{L} 1}$. The concentration drop from $C_{\mathrm{ArH}}^{i 2}$ to $C_{\mathrm{ArH}}^{\mathrm{L} 2}$ is relatively more important. Hence, the conditions under which the concentration drop of the aromatic compound transferred over the boundary layer in phase L2 is more than, for example, $5 \%$ must be checked. If this is the case, the simple approximation $C_{\mathrm{ArH}}^{i 2} \approx C_{\mathrm{ArH}}^{\mathrm{L} 2}$ starts to lead to inaccuracies [49]. To check this approximation it is possible to compare the rate of mass transfer with the chemical reaction:

$J_{\mathrm{ArH}} a V=k_{\mathrm{L} 2}\left(C_{\mathrm{ArH}}^{\mathrm{i} 2}-C_{\mathrm{ArH}}^{\mathrm{L} 2}\right) a V$

$J_{\mathrm{ArH}} a V=\epsilon_{\mathrm{L} 2} k_{2} C_{\mathrm{ArH}}^{\mathrm{i} 2} C_{\mathrm{HNO}_{3}}^{\mathrm{L} 2}$

where $\epsilon_{\mathrm{L} 2}$ refers to the volumetric fraction acid phase in which the reaction takes place, and $a$ is the interfacial area per unit volume.

The combination of both equations gives:

$\frac{\epsilon_{\mathrm{L} 2} k_{2} C_{\mathrm{HNO}_{3}}^{\mathrm{L} 2}}{k_{\mathrm{L} 2} a}=1-\frac{C_{\mathrm{Ar}}^{\mathrm{L} 2}}{C_{\mathrm{Ar} H}^{\mathrm{i} 2}}$

Table 5

Constants for the calculation of Eq. (37)

\begin{tabular}{lll}
\hline$b_{1}$ & $b_{2}$ & $b_{3}$ \\
\hline 1.6042 & -4.990 & $2.23 \times 10^{-3}$ \\
\hline
\end{tabular}

Hence, in the case where $C_{\mathrm{ArH}}^{i 2} \approx C_{\mathrm{ArH}}^{\mathrm{L2}}$, it must be checked that $k_{\mathrm{L} 2} a \gg \epsilon_{\mathrm{L} 2} k_{2} \mathrm{C}_{\mathrm{HNO}_{3}}$.

For the case where the transport of the aromatic compound in the reaction phase is not chemically enhanced and the concentration drop in the reaction phase is relatively small, it is possible to derive an overall reaction rate expression as [49]

$R=\epsilon_{\mathrm{L} 2} k_{2} C_{\mathrm{ArII}}^{\mathrm{L} 2} C_{\mathrm{INNO}}^{\mathrm{L} 2}$

In order to check the validity of these assumptions it is necessary to calculate, by means of empirical correlations, the diffusion and mass-transfer coefficients. Furthermore the interfacial area has to be obtained.

\subsection{The diffusion coefficients}

Despite different available theoretical treatments for the description of diffusion in liquids, there are hardly any satisfactory methods to predict the diffusion coefficients in multicomponent mixtures. Therefore, prediction procedures must be applied only when experimental data are not available. Such procedures can be divided into those suitable for non-electrolytes and those suitable for electrolytes.

For the diffusivity of aromatic compounds in mixed acid, as suggested by Chapman and Strachan [44], a modified version of the widely used correlation, recommended by Perkins and Geankoplis [50] to estimate the multicomponent diffusion coefficient in liquid mixtures, can be used:

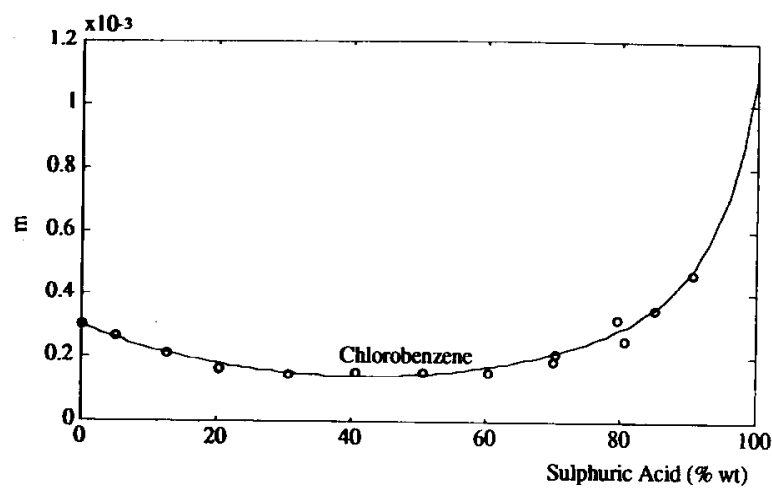

Fig. 12. Experimental $(O)$ and calculated (line) distribution coefficients for chlorobenzene in sulphuric acid solutions at $298.2 \mathrm{~K}$ based on Eqs. (34) and (35). Experimental data from Refs. [42,44]. 


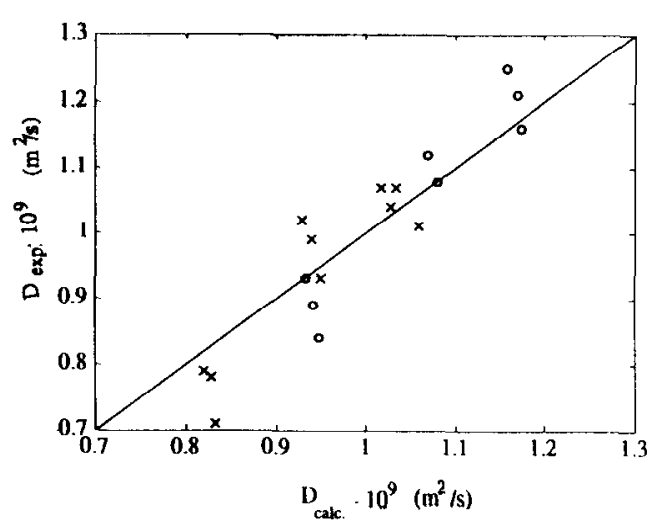

Fig. 13. Pariry plot of experimental and calculated diffusivities for toluene $(x)$ and benzene $(0)$ at $303.2 \mathrm{~K}$, for different mixed-acid compositions. Experimental data from Hanson and Ismail [51].

$D=\frac{F T}{\mu^{0.8}}$

where $F$ is given by:

$F=\frac{4.67 \times 10^{6}(\phi M)^{0.5}}{V_{\mathrm{b}}^{0.6}}$

and $V_{\mathrm{b}}$ in litres per mole is the total molal volume of the aromatic compound at its normal boiling point, and $\phi M$ is defined according to Cox and Strachan [26] as

$\phi M=2.6 x_{\mathrm{W}} M_{\mathrm{W}}+2.0 x_{\mathrm{S}} M_{\mathrm{S}}+1.05 x_{\mathrm{N}} M_{\mathrm{N}}$

where $x$ and $M$ are the mole fraction and molecular weight, respectively.

Values of $D$ for toluene and benzene were experimentally determined by Hanson and Ismail [51] using the laminar-jet technique. Fig. 13 shows the comparison between experimental and calculated diffusivities for toluene and benzene, using Eqs. (43)-(45).

\subsection{Mass-transfer coefficient}

Unfortunately, there is only one experimental value in literature for the mass-transfer coefficient in aromatic nitrations by mixed acid, $k_{\mathrm{L} 2}$ equal to $1.03 \times 10^{5} \mathrm{~m}$ $\mathrm{s}^{-1}$. This value was obtained by Chapman et al. [52] in a series of toluene nitration experiments using acid strengths between 76 and $79 \%$. In these experiments, the acid phase was the continuous one. This value is in agreement with typical values found in liquid-liquid systems; for example, Fernandes and Sharma [53] found values between 1.13 and $1.6 \times 10^{-5} \mathrm{~m} \mathrm{~s}^{-1}$ for the system $n$-hexylacetate and $1 \mathrm{M} \mathrm{NaOH}$ solution. The following empirical correlation developed by Calderbank and Moo-Young [54] and experimentally validated in a wide range of operating conditions [55] may be used to determine the mass-transfer coefficient in the continuous phase $k_{\mathrm{L} 2}$ in liquid--liquid dispersion systems [56]
$k_{\mathrm{L} 2}=0.13\left(\frac{P \mu_{\mathrm{c}}}{V_{\mathrm{d}} \rho_{\mathrm{c}}^{2}}\right)^{1 / 4}\left(\frac{\mu_{\mathrm{c}}}{\rho_{\mathrm{c}} D_{\mathrm{ArH}}}\right)^{-2.3}$

where $P$ refers to the power dissipated by the stirrer:

$P=N p \rho_{\mathrm{m}} n_{\mathrm{a}}^{3} D_{\mathrm{a}}^{5}$

In our reactor the impeller Reynolds number is always greater than $10^{4}$, hence $N p$ may be considered as a constant, $N p=2.2[7,57]$.

Using the correlation Eq. (44), and the experimental data from Chapman et al. [52], the value obtained for $k_{\mathrm{L} 2}$ is $1.1 \times 10^{-5} \mathrm{~m} \mathrm{~s}^{1}$ - see Appendices 4 and 5 for a calculation of the physical and transport properties - which is in agreement with the reported literature experiments.

\section{Isomer distribution}

Another aspect to consider in the mononitration of toluene and chlorobenzene is the isomer distribution. The relative reactivities of the ortho, meta and para carbon atoms should be proportional to the electron availability at these sites and the relative probability of collision with a given nitronium ion. At the same time, the reaction ratc measurements only consider the aromatic compound decay. Therefore the overall conversion rate obtained was split into partial rates for each isomer. The distribution of isomers depends on temperature and on the sulphuric acid strength.

The isomer distribution after reaction completion in the nitration of toluene was found to be 57.061 .0 , 3.4-4.2, and 34.0-38.0 molar\% for ortho-, meta- and para-nitrotoluene, respectively, depending on reaction conditions [6]. A rather weak dependence on the reactor temperature, still within the experimental error range, was observed for the selectivity ratios ortho/ para. A temperature rise from 15 to $45^{\circ} \mathrm{C}$ changes the values of this ratio at the end of the reaction from 1.69 to 1.76 , which is within the experimental error. Also an influence of the sulphuric acid strength was observed, and it was correlated in the range of $60-80 \mathrm{wt} \%$ as

$\frac{o-\mathrm{MNT}}{p-\mathrm{MNT}}=3.246-0.022 x$

Similar dependences have been found by Harris [58] and Barnet et al. [27]. They obtained a value of -0.021 for the slope in Eq. (48). The percentage of $m$-MNT was considered to be constant at $4 \%$.

In the nitration of chlorobenzene, the data from Coombes et al. [28] in the range of 68-74 wt.\% of sulphuric acid strength were used to obtain the isomer distribution in molar $\%$ as

$o-\mathrm{MNC}=1.22+0.466 x$

$m-\mathrm{MNC}=0.89-1.36 \times 10^{-3} x$ 
Table 6

Characteristics of the equipment

\begin{tabular}{lllllll}
\hline Vessel & $\begin{array}{l}\text { Diameter } \\
T(\mathrm{~mm})\end{array}$ & $\begin{array}{l}\text { Height } \\
H(\mathrm{~mm})\end{array}$ & $\begin{array}{l}\text { Volume } \\
V(\mathrm{I})\end{array}$ & $\begin{array}{l}\text { Agitator } \\
\text { type }\end{array}$ & $\begin{array}{l}\text { Impeller diameter } \\
D_{\mathrm{a}}(\mathrm{mm})\end{array}$ & $\begin{array}{l}\text { Impeller speed } \\
n_{\mathrm{a}}\left(\mathrm{s}^{-1}\right)\end{array}$ \\
\hline $\begin{array}{l}\text { Reactor } \\
\mathrm{RCl}\end{array}$ & 115 & 200 & 2.0 & FB45IP & 59 & $6.6-13.3$ \\
\hline
\end{tabular}

aFB45IP: four-bladed $45^{\circ}$ inclined paddle, unbaffled

$p-\mathrm{MNC}=97.89-0.467 x$

\section{Experimental study: model verification with reaction calorimetry}

The mathematical model for the nitration rates as described above was developed using data from homogeneous experiments with low nitric acid concentrations between $10^{-4}$ and $10^{-2} \mathrm{~mol}^{-1}$. In order to validate this model also under heterogeneous conditions, a series of experiments were carried out in a reaction calorimeter $\mathrm{RCl}$ from Mettler, see Table 6. This apparatus provides an accurate measurement of the heat removal from the reactor, which through a heat balance is used to deduce the rate of heat generation in a certain reaction mass, and hence the rate of reaction. The precision of this calorimetric method depends on the correct representation of all the secondary heat effects such as heat losses, stirring power supply, heat taken up by reactor wall and dilution heat [8]. In this particular case, the heat of dilution, which cannot be neglected as part of the total heat generated during the nitration, was evaluated using a model developed in previous work [59].

The experiments in the reaction calorimeter were carried out in such a way as to assure the overall conversion rate is always controlled by chemical reaction. This is accomplished by using sulphuric acid of a low strength, between $60-62 \mathrm{wt} . \%$, for industrial aromatic mononitrations. The operating conditions are summarized in Table 7, where the maximum Hatta number calculated is also included. The calculated diffusivity coefficients as well as the mass-transfer coefficient discussed above were used to check the validity of the assumptions that $\mathrm{Ha}<0.3$ and

Table 7

Isothermal nitration experiments in the kinetic regime: initial and operating conditions

\begin{tabular}{llllll}
\hline Compound & $\begin{array}{l}\text { Temperature } \\
(\mathrm{K})\end{array}$ & $\begin{array}{l}x \\
(\mathrm{wt} . \%)\end{array}$ & $\begin{array}{l}n_{\mathrm{a}} \\
\left(\mathrm{s}^{-1}\right)\end{array}$ & $\begin{array}{l}\text { Feeding } \\
\text { time }\end{array}$ & $\begin{array}{l}\text { Ha } \mathrm{a}_{\text {calc }} \\
(\text { max. }\end{array}$ \\
\hline Benzene & 298.2 & 62.0 & 6.67 & Batch & 0.2 \\
Toluene & 308.2 & 61.4 & 6.67 & Batch & 0.03 \\
Chlorobenzene & 328.2 & 62.0 & 6.67 & Batch & 0.2 \\
\hline
\end{tabular}

$k_{\mathrm{L} 2} a \gg \epsilon_{\mathrm{L} 2} k_{2} C_{\mathrm{HNO}_{3}}^{\mathrm{L} 2}$ during the reaction, and that the reaction rate expression Eq. (42) is correct under the experimental conditions. In a typical case, $k_{\mathrm{L} 2} \approx 10^{-5}$ $\mathrm{m} \mathrm{s}^{-1}, a \approx 4 \times 10^{3} \mathrm{~m}^{2} \mathrm{~m}^{-3}[60], D_{\mathrm{ArH}} \approx 10^{-9} \mathrm{~m}^{2} \mathrm{~s}^{-1}$, $\epsilon_{\mathrm{L} 2} \approx 0.8, C_{\mathrm{HNO}_{3}}^{\mathrm{L} 2} 2 \mathrm{M}$, and $k_{2} \approx 10^{-4} 1 \mathrm{~mol}^{-1} \mathrm{~s}^{-1}$, so the assumptions are valid.

Selectivity and yields were determined directly from the concentration measurements by gas chromatography (GC) [6], whereas the reaction rate was estimated independently from calorimetric measurements [8].
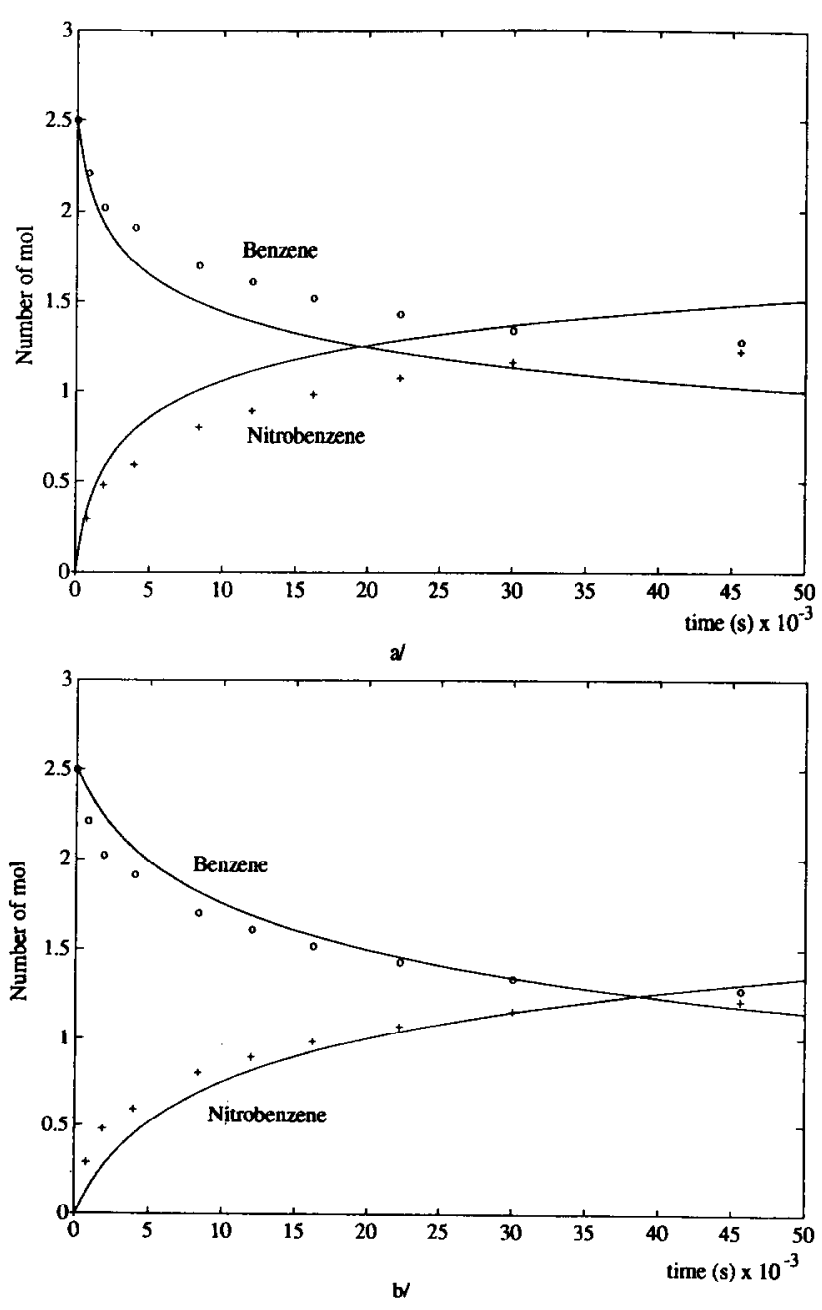

Fig. 14. Experimental and simulated molar concentrations for benzene $(O)$ and nitrobenzene $(+)$ as a function of time during a batch nitration: (a) using the $H_{\mathrm{R}}$ function; (b) using the $M_{\mathrm{c}}$ function. 

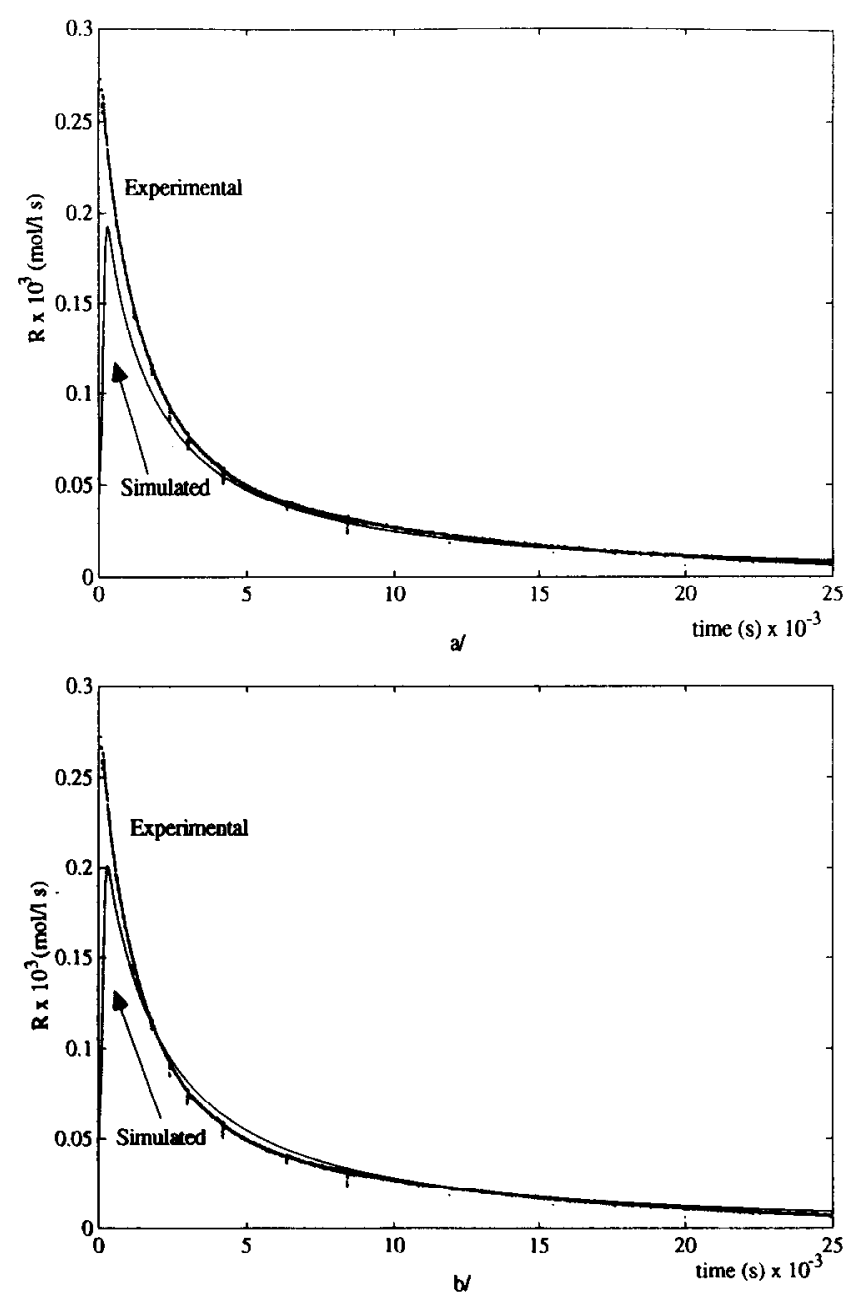

Fig. 15. Experimental and simulated reaction rate for batch toluene mononitration: (a) using the $H_{\mathrm{R}}$ function; (b) using the $M_{\mathrm{c}}$ function.

Figs. 14-17 show experimental results and simulations using the $H_{\mathrm{R}}$ and the $M_{\mathrm{c}}$ acidity functions. Fig. 14 shows the concentration profiles during the nitration of benzene. In this experiment, $195 \mathrm{~g}$ of henzene were added batchwise to $868 \mathrm{~g}$ of mixed acid with a $\mathrm{H}_{2} \mathrm{SO}_{4}$ strength of $62.0 \mathrm{wt} . \%$. The reactor temperature setpoint was $298.2 \mathrm{~K}$ and the stirrer speed was $6.67 \mathrm{~s}^{-1}$. Figs. 15 and 16 show the concentration profiles, obtained by GC, and the overall conversion rates, obtained by calorimetric measurements, for the nitration of toluene. As can be seen, the agreement between these two independent measurements is satisfactory. The nitration of toluene was carried out at $308.2 \mathrm{~K}$ and the stirrer speed was $6.67 \mathrm{~s}^{-1}$. The procedure was identical to the one described above for benzene, i.e. $184 \mathrm{~g}$ of toluene were added batchwise to $1870 \mathrm{~g}$ of mixed acid with a $\mathrm{H}_{2} \mathrm{SO}_{4}$ strength of 61.4 wt.\%. Fig. 17 shows the concentration profiles during a nitration of chlorobenzene which was carried out at $328.2 \mathrm{~K}$ and a stirrer speed of $6.67 \mathrm{~s}^{-1}$. In this experiment, $281 \mathrm{~g}$ of chlorobenzene were added batchwise to $851 \mathrm{~g}$ of mixed acid with a $\mathrm{H}_{2} \mathrm{SO}_{4}$ strength of $62.0 \mathrm{wt} . \%$.
The concentration profiles show the behaviour is not that of a typical second-order reaction, since the rate of consumption decreases more rapidly; this is due to the fact that the concentration of the nitronium ion decreases as water is produced. The differences between the experimental and simulated conversion rates at the beginning of the toluene nitration experiment are due to the slow conversion rates measured. Under such conditions, small errors in the evaluation of the heat capacity become important, since the reactor temperature is not stabilized and its derivative is not zero.

From comparisons between model and experimental results it can be concluded that it is possible to extrapolate to heterogenous reactions in the kinetic regime of a slow liquid-liquid reaction using data from homogeneous nitration experiments; it is also possible to interpret the dynamic behaviour of discontinuous nitration processes in such conditions.
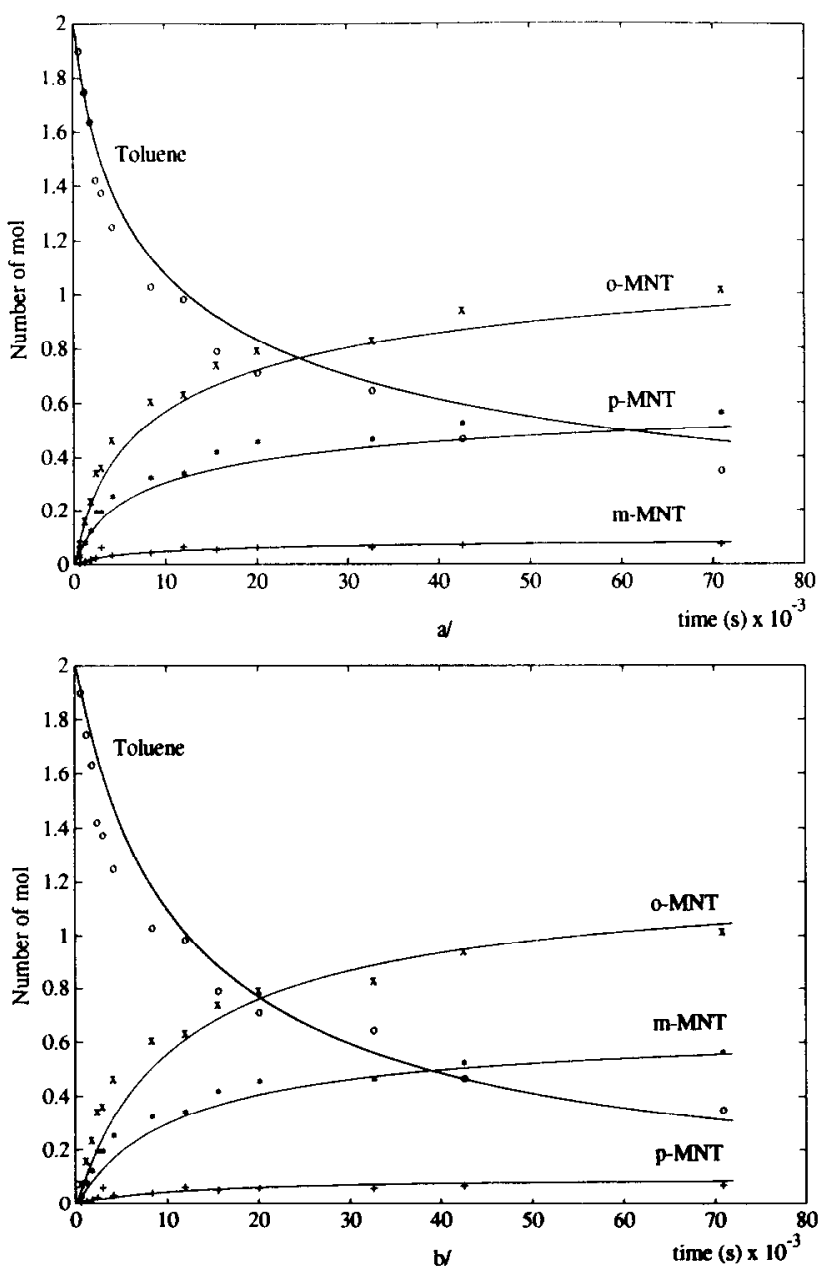

Fig. 16. Experimental and simulated molar concentrations for $(0)$ toluene, $(x) o$-nitrotoluene $(o-\mathrm{MNT})(+), m$-nitrotoluene $(m-$ $\mathrm{MNT}$ ), and $\left(^{*}\right) p$-nitrotoluene ( $p$-MNT) as a function of time for a batch nitration: (a) using the $H_{\mathrm{R}}$ function; (b) using the $M_{\mathrm{c}}$ function. 

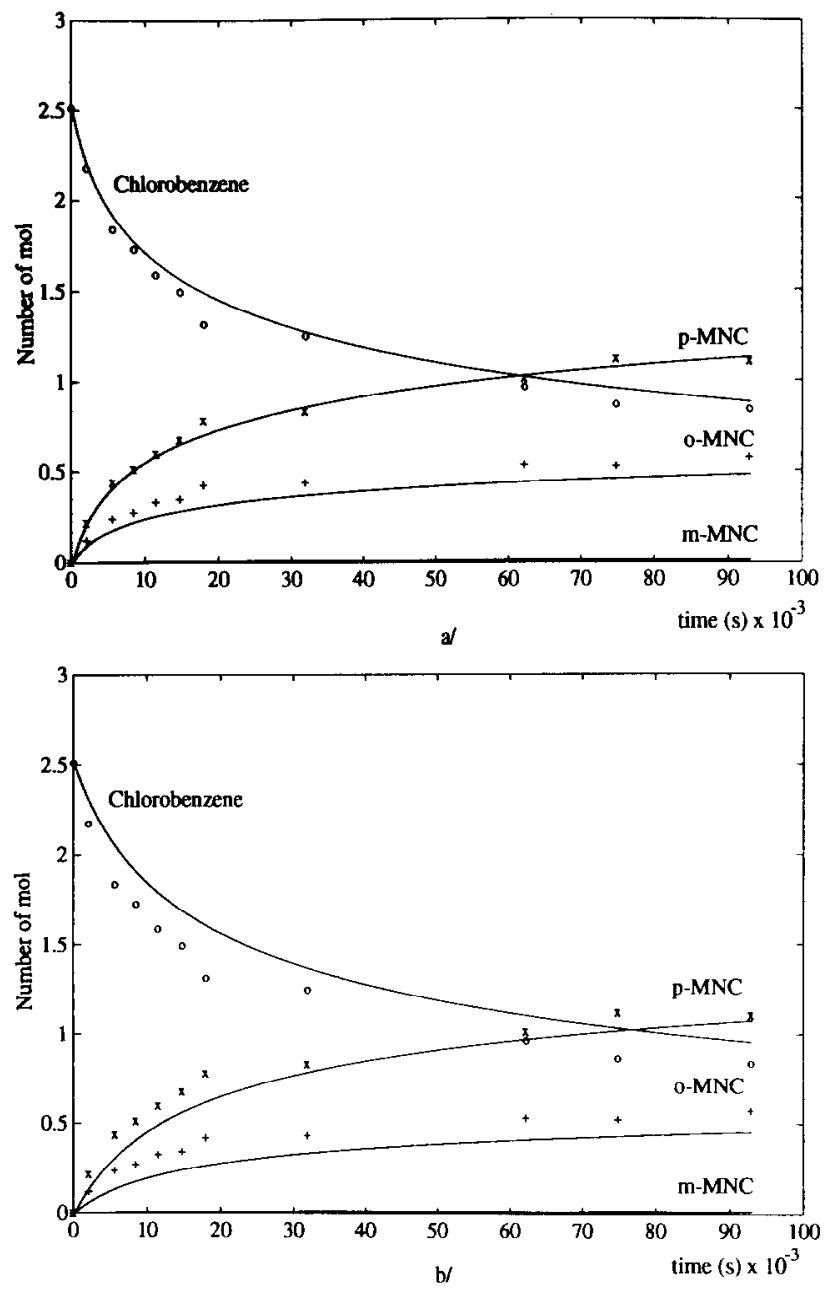

Fig. 17. Experimental and simulated molar concentrations for $(O)$ chlorobenzene, $(+)$ ortho-chloronitrobenzene $(o-\mathrm{MNC}),(\times)$ p-nitrochlorobenzene $(p-\mathrm{MNC})$, and $m-\mathrm{MNC}$ as a function of time during a batch nitration: (a) using the $I_{\mathrm{R}}$ function; (b) using the $M_{\mathrm{o}}$ function.

\section{Discussion and conclusions}

The main objective of this paper was to analyse the possibility of extrapolating experimental data obtained from homogeneous nitration experiments - with nitric acid concentrations between $10^{-4}$ and $10^{-2}$, and a temperature of $298.2 \mathrm{~K}$ - to discontinuous heterogeneous nitrations under conditions of high nitric acid concentrations and temperatures other than $298.2 \mathrm{~K}$. Under such conditions, the composition of the acid phase is different from that used in the mechanistic studies analysed so far, and the nitration rates available from the latter are not immediately relevant to the former. Furthermore, in discontinuous nitrations the process is even more complex, because the two phases change in composition as the reaction proceeds and therefore all the relevant parameters like reaction rate constant, acidity of the acid phase, diffusivity of aromatic compounds, mass-transfer coefficient, interfacial area, interfacial tension and physical and transport properties change. For these reasons, the first necessary step was to validate the model in the kinetic regime in which mass-transfer resistance does not have an influence on the overall conversion rate - where the only important parameters are the reaction rate constant and the solubility of the aromatic compound in the mixed acid.

From the comparisons between model and experimental results it can be concluded that it is possible to extrapolate data from homogeneous nitration experiments and to interpret the dynamic behaviour of discontinuous nitration processes in the kinetic regime of slow liquid-liquid reactions. The $H_{\mathrm{R}}$ function produces acceptable results in the acidity range studied, of 60 to 62 wt.\% sulphuric acid; it is clear from Fig. 6 that at high acidity values the results become inaccurate [14]. This is the case for deactivated aromatic rings, e.g. in di- and trinitrations, for which it is necessary to work between 80 and $100 \mathrm{wt} . \%$ sulphuric acid strength to obtain significant conversion rates. This may be corrected by adjusting $K$ in Eq. (10) to take into account such behaviour, but always the necessity remains of introducing monohydrated nitric acid for the determination of the reaction rates, even in the regions where practically no water is present.

Even though we are able to calculate correctly the reaction rate constant in a wide acidity range with the $M_{\mathrm{c}}$ function, for the determination of the kinetic function it is still difficult to extend these results to temperatures other than $298.2 \mathrm{~K}$, since less experimental data are available when compared to the $H_{\mathrm{R}}$ function. In particular, more data on the temperature dependence of the dissociation constant of nitric acid and the formation of nitronium ion are required, as well as the temperature variation of the $M_{\mathrm{c}}$ function. Despite this, the results are acceptable within the range of temperatures studied, of 298.2 to $328.2 \mathrm{~K}$. Future work will be dedicated to the acquisition of the temperature dependence data to apply the $M_{\mathrm{c}}$ function.

In a second part of this work, the determination of the effective interfacial area and the mass-transfer-controlled region will be evaluated.

\section{Acknowledgements}

The authors are most grateful to Professor N.C. Marziano and Dr. J. Sanders for their valuable comments and suggestions, and to Dr. C. Barcons and J. Ligthart for their collaboration during the experiments.

\section{Appendix 1. Activity coefficients in $\mathrm{HNO}_{3}-\mathrm{H}_{2} \mathrm{SO}_{4}-$ $\mathrm{H}_{2} \mathrm{O}$ mixtures}

In recent years considerable attention has been paid 
Table Al

Wilson's energy constants (cal $\left.\mathrm{g}^{-1} \mathrm{~mol}^{-1}\right)$ and parameters $(P=1$ bar)

\begin{tabular}{llclll}
\hline Binary system & $\lambda_{12}-\lambda_{11}$ & $\lambda_{21}-\lambda_{22}$ & $A_{12}$ & $A_{21}$ & $T(\mathrm{~K})$ \\
\hline $\mathrm{HNO}_{3}-\mathrm{H}_{2} \mathrm{O}$ & -1309.58 & -971.42 & 3.8 & 12.38 & 298.2 \\
$\mathrm{H}_{2} \mathrm{SO}_{4}-\mathrm{H}_{2} \mathrm{O}$ & -3870.0 & -1812.0 & 9.97 & 12.06 & 581.3 \\
$\mathrm{HNO}_{3}-\mathrm{H}_{2} \mathrm{SO}_{4}$ & -1127.85 & 1127.85 & 8.56 & 0.117 & 298.2 \\
\hline
\end{tabular}

to activity coefficients in aqueous mixtures of electrolytes (see Refs. [61,62], among others). Unfortunately, this is still an open area of research, and data required for such correlations to be applied for the mixed-acid system are not available at the moment. As a consequence, a compromise has to be made to avoid unnecessary and complex calculations: in using the Wilson method, see Al-Khudhairy and Zaldivar [63].

An important characteristic of the Wilson equation is that no specific interaction parameters for ternary systems are required, and that it uses only two temperature-dependent terms to describe the binary system: this reduces the quantity of experimental data to characterize a multi-component solution. The Wilson expression for the liquid-phase activity coefficient in a multicomponent system, assuming pure substance as standard state, is

$$
\ln \gamma_{k}=1-\ln \left(\sum_{j=1}^{n} x_{j} A_{k j}\right)-\sum_{i=1}^{n} \frac{x_{i} A_{i k}}{\sum_{j=1}^{n} x_{j} A_{i j}}
$$

where

$A_{i j}=\frac{v_{j}^{\mathrm{L}}}{v_{i}^{\mathrm{L}}} \exp \left[\frac{-\left(\lambda_{i j}-\lambda_{i j}\right)}{R T}\right]$

and $v^{\mathrm{L}}$ refers to the liquid molar volume. In general, it is assumed that $\Lambda_{i j} \neq \Lambda_{j i}, \Lambda_{i i}=\Lambda_{j j}=1$ and $\lambda_{i j}=\lambda_{j i}$.

The Wilson parameters $\Lambda_{i j}$ for the binary systems $\mathrm{HNO}_{3}-\mathrm{H}_{2} \mathrm{O}, \mathrm{H}_{2} \mathrm{SO}_{4}-\mathrm{H}_{2} \mathrm{O}$ and $\mathrm{HNO}_{3}-\mathrm{H}_{2} \mathrm{SO}_{4}$ were calculated from a series of experimental isothermal and isobaric vapour liquid equilibrium data points by means of the corrected Gauss-Newton non-linear leastsquares method in conjunction with either of the following objective functions $O F$

$$
\begin{aligned}
& \mathrm{OF}=\sum_{i=1}^{n}\left(\frac{P_{\exp }-P_{\text {calc }}}{P_{\exp }}\right)_{i}^{2} \\
& \mathrm{OF}=\sum_{i=1}^{n}\left(1-y_{1 \text { calc }}-y_{2 \text { calc }}\right)_{i}^{2}
\end{aligned}
$$

The calculation of the objective functions given in Eqs. $(\Lambda 3)$ and $(\Lambda 4)$ requires only the values of $x$ and the total pressure at constant temperature, or the values of $y$ and temperature at constant total pressure. The values are listed in Table A1. The experimental data sets used were isothermal data at $298.2 \mathrm{~K}$ from Hàla et al. [64] for the nitric acid-water system and for the sulphuric acid-water system, and further data from Bosen and Engels [65]. Vapour-liquid equilibria data for the nitric acid-sulphuric acid system are extremely scarce owing to the impossibility of obtaining pure anhydrous sulphuric acid under normal conditions. A series of liquid activity coefficients over a range of liquid compositions at $298.2 \mathrm{~K}$ in the binary mixture $\mathrm{HNO}_{3}-\mathrm{H}_{2} \mathrm{SO}_{4}$ were found in Ref. [66]. The ternary system was checked against experimental data from Ref. [67], showing that the calculated activity coefficients for nitric acid and water were in good agreement with the experimental values [63]. Future efforts should be directed towards the use of more realistic functions that correctly represent the complex behaviour of nitric acid, sulphuric and water mixtures.

\section{Appendix 2. Calculation of the reaction rate constant $k_{2}^{\prime}$ for chlorobenzene at different temperatures using the $H_{\mathrm{R}}$ function}

In order to derive the reaction rate constant $k_{2}^{\prime}$ related to the mechanism described in this paper, it is necessary to assume this constant is independent of the acidity of the acid phase and only depends on the aromatic compound and the temperature:

$$
\begin{aligned}
\log k_{2}^{\prime}= & \log k_{2}-\log K-\log \gamma_{\mathrm{HNO}_{3} \mathrm{H}_{2} \mathrm{O}} \\
& +\left(H_{\mathrm{R}}+\log a_{\mathrm{H}_{2} \mathrm{O}}\right)
\end{aligned}
$$

Table A2 and Fig. A1 illustrate for chlorobenzene the calculation of $k_{2}^{\prime}$ using experimental data at different temperatures.

Table A2

Calculation of the temperature dependence of $k_{2}^{\prime}$ as a function of experimental data, for chlorobenzene

\begin{tabular}{llllllll}
\hline$T(\mathrm{~K})$ & $x$ & $C_{\mathrm{HNO}_{3}}$ & $\log k_{2}$ & $\left(H_{\mathrm{R}}+\log a_{\mathrm{H}_{2} \mathrm{O}}\right)$ & $\log K$ & $\log \gamma_{\mathrm{HNO}_{3}-\mathrm{H}_{2} \mathrm{O}}$ & $\log k_{2}^{\prime}$ \\
\hline 288.2 & 79.45 & 0.019 & 2.111 & -17.017 & -5.630 & -0.178 & -9.099 \\
298.2 & 79.45 & 0.019 & 2.408 & -15.950 & -5.441 & -0.191 & -7.910 \\
308.2 & 79.45 & 0.019 & 2.657 & -14.953 & -5.264 & -0.205 & -6.826 \\
318.2 & 79.45 & 0.019 & 2.971 & -14.018 & -5.099 & -0.219 & -5.729 \\
328.2 & 79.45 & 0.019 & 3.086 & -13.140 & -4.943 & -0.232 & -4.878 \\
\hline
\end{tabular}




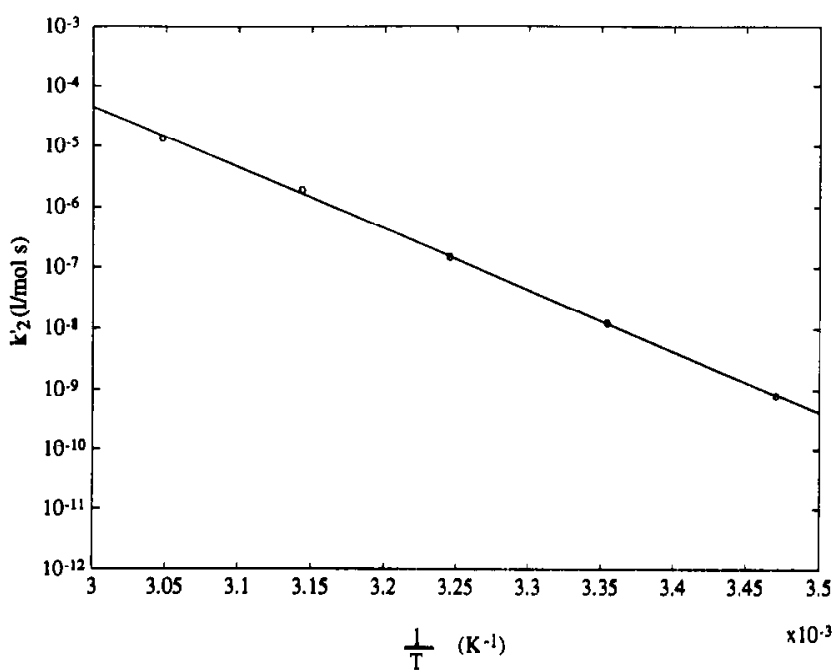

Fig. A1. Arrhenius plot of $k_{2}^{\prime}$ for chlorobenzene. Experimental data from Chapman and Strachan [44]. $\ln A=59.451, E_{\mathrm{a}} / R=23160$.

Appendix 3. Calculation of the reaction rate constant $k_{2}^{\prime}$ for toluene at different temperatures using the $M_{\mathrm{c}}$ function

In order to derive the reaction rate constant $k_{2}^{\prime}$ and $n$ related to the mechanism described in this paper, it is necessary to assume that $k_{2}^{\prime}$ is independent of the acidity of the acid phase and only depends on the aromatic compound and the temperature:

$$
\begin{aligned}
\log k_{2}^{\prime}-n M_{\mathrm{c}} & =\log k_{2} \\
& +\log \left(\frac{K_{\mathrm{HNO}_{3}}}{C_{\mathrm{H}^{+}} 10^{-0.571 M_{\mathrm{c}}}}+\frac{C_{\mathrm{H}^{+}} 10^{-2.542 M_{\mathrm{c}}}}{a_{\mathrm{H}_{2} \mathrm{O}} K_{\mathrm{NO}_{2}^{+}}}+1\right) \\
& +\log \frac{a_{\mathrm{H}_{2} \mathrm{O}} K_{\mathrm{NO}_{2}^{+}}}{C_{\mathrm{H}^{+}} 10^{-2.542 M_{\mathrm{c}}}}
\end{aligned}
$$

Table A3 and Fig. A2 illustrate for toluene the calculation of $k_{2}^{\prime}$ using experimental data at different temperatures.

For benzene the Arrhenius plot was calculated from $E_{\text {a }}$ and $A$ values reported by Coombes et al. [13].

\section{Appendix 4. Physical and transport properties in $\mathrm{HNO}_{3}-\mathrm{H}_{2} \mathrm{SO}_{4}-\mathrm{H}_{2} \mathrm{O}$ mixtures}

The following correlations were employed to calcu- late the physical and transport properties for the mixed acid:

Volume. The volume of the mixed acid as a function of composition and temperature was calculated with:

$V=\sum_{i=1}^{3} n_{i} v_{i}^{\mathrm{L}}$

where $v_{i}^{\mathrm{L}}$ refers to the liquid molar volume of the $i$ th compound, which can be correlated by

$v_{i}^{\mathrm{L}}=A B^{(1-T / C)^{0.2857}}$

where $A, B$ and $C$ are the constants given in Table A4, as obtained by fitting experimental data from Miller et al. [24] and from Perry and Chilton [69].

Viscosity. The expression of Van Velzen et al. [70] was used for pure liquids,

$\log \mu_{i}=B\left(\frac{1}{T}-\frac{1}{T_{0}}\right)$

where $B$ and $T_{0}$ are the constants as given in Table A5, and as obtaincd from experimental data in Ref. [69].

The total viscosity in terms of individual viscosities was calculated using

$\log \mu_{\mathrm{T}}=\sum_{i=1}^{3} x_{i} \log \mu_{i}$

where $x_{i}$ refers to the weight percent of the compound. The viscosity obtained by Eq. (A10) has been corrected by us using experimental data from Refs. [71,72]: to this end, we used a second-order polynomial expression

$\mu_{\text {mixed acid }}=9.676-2.516 \mu_{\mathrm{T}}+0.315 \mu_{\mathrm{T}}^{2}$

where the viscosity is expressed in centipoises.

\section{Appendix 5. Physical and transport properties of the organic phase}

The following correlations were employed to calculate the physical and transport properties of the organic phase mixtures:

Table A3

Calculation of the temperature dependence of $k_{2}^{\prime}$ as a function of experimental data, for toluene

\begin{tabular}{lllllll}
\hline$T(\mathrm{~K})$ & $x$ & $C_{\mathrm{HNO}_{3}}$ & $\log k_{2}$ & $n M_{\mathrm{c}}$ & $\log v a l_{1}+\log v a l_{2}$ & $\log k_{2}^{\prime}$ \\
\hline 288.2 & 70.2 & 0.013 & 3.2095 & -0.7712 & 4.052 & 6.4904 \\
293.2 & 70.2 & 0.013 & 3.3674 & -0.7548 & 4.002 & 6.6148 \\
298.2 & 70.2 & 0.013 & 3.5276 & -0.7388 & 3.954 & 6.7430 \\
303.2 & 70.2 & 0.013 & 3.7193 & -0.7234 & 3.908 & 6.9039 \\
308.2 & 70.2 & 0.013 & 3.8000 & -0.7084 & 3.863 & 6.9550 \\
\hline
\end{tabular}




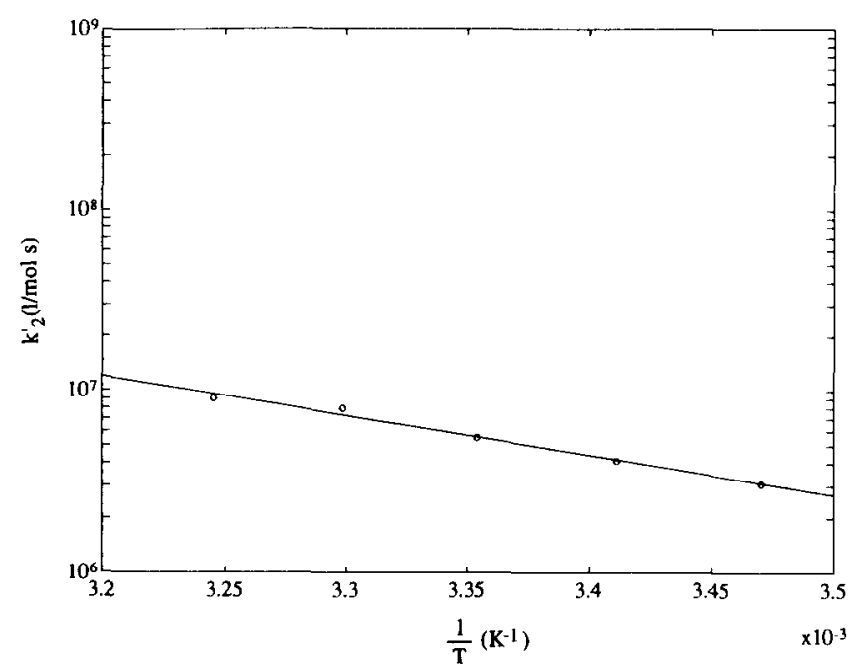

Fig. A2. Arrhenius plot of $k_{2}^{\prime}$ for toluene. Experimental data from Sheats and Strachan [68]. $\ln A=32.264, E_{\mathrm{a}} / R=4990$.

Table A4

Constants for the calculation of mixed acid volume

\begin{tabular}{llll}
\hline Compound & $A$ & $B$ & $C$ \\
\hline $\mathrm{H}_{2} \mathrm{O}$ & 0.0458 & 0.3099 & 647.4 \\
$\mathrm{HNO}_{3}$ & 0.1187 & 0.2508 & 580.1 \\
$\mathrm{H}_{2} \mathrm{SO}_{4}$ & 0.1910 & 0.2212 & 995.4 \\
\hline
\end{tabular}

Volume. Eqs. (A7) and (A8) were used for the calculation of the volume of the organic phase mixtures. The values for the constants $A, B$ and $C$ are given in Table A6.

Viscosity. Fq. (A9) was used for the calculation of the viscosity of the pure compounds in the organic phase. The values for the constants $B$ and $T_{0}$ are given in Table A7.

The viscosity of the organic phase itself was calculated with Eq. (A10).

\section{Appendix 6. Notation}

$A \quad$ activation energy

a activity ( $\left.\mathrm{mol} \mathrm{l}^{-1}\right)$

a interfacial area $\left(\mathrm{m}^{2} \mathrm{~m}^{-3}\right)$

C concentration $\left(\mathrm{mol}^{-1}\right)$

$d_{32} \quad$ droplets Sauter mean diameter $(\mathrm{m})$

$D \quad$ stirrer diameter $(\mathrm{m})$

$D_{\text {ArH }}$ diffusivity of aromatic compound $\left(\mathrm{m}^{2} \mathrm{~s}^{-1}\right)$

$\mathrm{Ha}$ Hatta number

$H_{\mathrm{R}} \quad$ acidity function

$H_{0} \quad$ Hammett's acidity function

$J_{\mathrm{ArH}}$ mass-transfer rate $\left(\mathrm{mol} \mathrm{m} \mathrm{m}^{-2} \mathrm{~s}^{-1}\right)$

$k_{2}^{\prime}$ reaction rate constant related to mechanism, see text $\left(1 \mathrm{~mol}^{-1} \mathrm{~s}^{-1}\right)$
Table A5

Constants for the calculation of mixed acid viscosity

\begin{tabular}{lcc}
\hline Compound & $B$ & $T_{0}$ \\
\hline $\mathrm{H}_{2} \mathrm{O}$ & 80.239 & 139.78 \\
$\mathrm{HNO}_{3}$ & 843.16 & 147.16 \\
$\mathrm{H}_{2} \mathrm{SO}_{4}$ & 1235.2 & 211.74 \\
\hline
\end{tabular}

Table A6

Constants for the calculation of the organic phase volume

\begin{tabular}{llll}
\hline Compound & $A$ & $B$ & $C$ \\
\hline Benzene & $2.560 \times 10^{-1}$ & 0.271 & 562.2 \\
Nitrobenzene & $3.354 \times 10^{-1}$ & 0.251 & 712.0 \\
Toluene & $3.195 \times 10^{-1}$ & 0.262 & 592.0 \\
$o$-MNT & $3.976 \times 10^{-1}$ & 0.248 & 720.0 \\
$m$-MNT & $3.976 \times 10^{-1}$ & 0.248 & 725.0 \\
$p$-MNT & $3.976 \times 10^{-1}$ & 0.248 & 735.0 \\
Chlorobenzene & $3.037 \times 10^{-1}$ & 0.271 & 632.4 \\
$o$-MNC & $8.682 \times 10^{-3}$ & 0.0 & 805.9 \\
$m$-MNC & $8.524 \times 10^{-3}$ & 0.0 & 789.7 \\
$p$-MNC & $8.238 \times 10^{-3}$ & 0.0 & 799.8 \\
\hline
\end{tabular}

$k_{2} \quad$ measured second-order rate constant $\left(1 \mathrm{~mol}^{-1}\right.$

$\mathrm{s}^{-1}$ )

$k_{\mathrm{L} 2} \quad$ mass-transfer coefficient $\left(\mathrm{m} \mathrm{s}^{-1}\right)$

$K \quad$ equilibrium constant

$m \quad$ distribution coefficient

$M \quad$ molecular weight $\left(\mathrm{g} \mathrm{mol}^{-1}\right)$

$M_{\mathrm{c}} \quad$ empirical activity coefficient

MNT mono-nitro-toluene

MNC mono-nitro-chlorobenzene

$n \quad$ stirrer speed $\left(\mathrm{s}^{-1}\right)$

$P \quad$ power dissipated by the stirrer (W)

$R \quad$ overall conversion rate based on the total reaction volume $\left(\mathrm{mol} \mathrm{1}^{-1} \mathrm{~s}^{-1}\right)$

$r \quad$ reaction rate in the acid phase $\left(\mathrm{mol} \mathrm{l}^{-1} \mathrm{~s}^{-1}\right)$

$T \quad$ temperature $(\mathrm{K})$

$V \quad$ volume (l)

We Weber number

$x \quad$ sulphuric acid strength or molar fraction

Greek letters

$\epsilon \quad$ dispersed phase volume fraction

$\gamma \quad$ activity coefficient

$\mu \quad$ viscosity $\left(\mathrm{kg} \mathrm{m}^{-1} \mathrm{~s}^{-1}\right)$

$\rho$ density $\left(\mathrm{kg} \mathrm{m}^{-3}\right)$

\section{Subscripts and superscripts}

\section{a stirrer}

ArH aromatic compound

c continuous phase

d dispersed phase

e heat-transfer fluid 
Table A7

Constants for the calculation of the organic phase viscosity

\begin{tabular}{llr}
\hline Compound & $B$ & \multicolumn{1}{l}{$T_{0}$} \\
\hline Benzene & 555.61 & 136.20 \\
Nitrobenzene & 735.54 & 174.88 \\
Toluene & 484.90 & 99.26 \\
$o$-MNT & 754.37 & 145.32 \\
$m$-MNT & 716.39 & 140.86 \\
$p$-MNT & 680.15 & 137.06 \\
Chlorobenzene & 497.81 & 103.93 \\
$o$-MNC & 691.38 & 179.27 \\
$m$-MNC & 691.38 & 179.27 \\
$p$-MNC & 691.38 & 179.27 \\
\hline
\end{tabular}

i1 organic interphase

i2 acid (aqueous) interphase

L1 organic phase

L2 acid (aqueous) phase

$\mathrm{m}$ reacting mixture

$\mathrm{N} \quad$ nitric acid

S sulphuric acid

W water

$\ddagger \quad$ activated transition intermediate

\section{References}

[1] C.K. Ingold, Structure and Mechanism in Organic Chemistry, Bell, London, 1953, Chapter 6.

[2] J.A. Barton and P.F. Nolan, Runaway reactions in batch reactors, The Protection of Exothermic Reactors and Pressurised Storage Vessels, IChemE Symp. Series, 85, 1984, pp. 13-21.

[3] J. Singh, PHI-TEC: Enhanced vent sizing calorimeter, in Int. Symp. on Runaway Reactions, AIChE, New York, 1989, pp. 313-330.

[4] R. Reisen and B. Grob, Reaction calorimetry in chemical process development, Swiss Chem., 7 (1985) 39-43.

[5] H. Hernández and J.M. Zaldivar, The JRC FIRES Project for investigations on runaway reactions, Eurotherm Seminar 14, Proc. Heat Transfer Major Technol. Hazards, 13 (1990) 1-10.

[6] E.J. Molga, C. Barcons and J.M. Zaldivar, Mononitration of toluene and quantitative determination of the isomer distribution by gas chromatography, Afinidad, 50 (1993) 15-20.

[7] J.M. Zaldivar, H. Hernández and C. Barcons, Development of a numerical simulator for a reaction calorimeter. FISIM, RC1 version, TN 1.90.109, 1990 (Joint Research Centre, Ispra Site, Italy).

[8] H. Hernández, J.M. Zaldivar and C. Barcons, Development of a mathematical model and a numerical simulator for the analysis and optimization of batch reactors, Comput. Chem. Eng., 17S (1993) 45-50.

[9] K. Schofield, Aromatic Nitration, Cambridge University Press, Cambridge, UK, 1980.

[10] G.A. Olah, R. Malhotra and S.C. Narang, Nitration: Methods and Mechanisms, VCH Publishers, New York, 1989.

[11] L.F. Albright and C. Hanson (eds.), Industrial and Laboratory Nitrations, ACS Symp. Series, 22, Washington, DC, 1976.

[12] N.C. Deno and R. Stein, Carbonium ions III. Aromatic nitration and the $C_{0}$ acidity function, $J . A C S, 78$ (1956) 578-581.

[13] R.G. Coombes, R.B. Moodie and K. Schofield, Electrophilic aromatic substitution. Part $\mathrm{I}$. The nitration of some reactive aromatic compounds in concentrated sulphuric and perchloric acids, J. Chem. Soc. B (1968) 800-804.

[14] N.C. Marziano, A. Zingales and V. Ferlito, A reinvestigation of nitration in aqueous sulfuric acid of benzene and halogenobenzenes, J. Org. Chem., 42 (1977) 2511-2513.

[15] N.C. Marziano, M. Sampoli, F. Pinna and A. Passerini, Thermodynamic nitration rates of aromatic compounds. Part 2. Linear description of rate profiles for the nitration of aromatic compouns in the range 40-98 wt.\% sulphuric acid, J. Chem. Soc., Perkin Trans. 2 (1984) 1163-1166.

[16] N.C. Marziano, P.G. Traverso and G.G. Cimino, Thermodynamic nitration rates of aromatic compounds. Part 1 . The nitration of benzene and some benzene derivatives in aqueous sulphuric and perchloric scids. A comparison of the results referred to water as standard state, J. Chem. Soc., Perkin Trans. 2 (1980) 574-578.

[17] J.P. Field and A.N. Strachan, Dependence of the rate constant and activation energy of aromatic nitration on mixed acid composition, Ind. Eng. Chem. Prod. Res. Dev., 21 (1982) 352-355.

[18] R.B. Moodie, K. Schofield and P. Taylor, Electrophilic aromatic substitution. Part 21. Rate constants for formation of nitronium ion in aqueous sulphuric, perchloric, and methane-sulphonic acids, J. Chem. Soc., Perkin Trans. 2 (1979) 133-136.

[19] C.H. Kochester, Acidity Functions, Academic Press, London, 1970.

[20] J.G. Hoggett, R.B. Moodie, J.R. Penton and K. Schofield, Nitration and Aromatic Reactivity, Cambridge University Press, Cambridge, UK, 1971.

[21] Lowen et al., 1950.

[22] M.J. Cook, A.R. Johnson, A.R. Katritzky and T.W. Toone, Temperature variation of the $H_{\mathrm{R}}$ acidity function in aqueous sulfuric acid, $J . A C S, 97$ (1975) 760-764.

[23] J.M. Kanhere and S.B. Chandalia, Kinetics of nitration of aromatic compounds with mixed acid: reinterpretation of published data, Ind. Eng. Chem. Proc. Des. Dev., 20 (1981) 404-407.

[24] R.C. Miller, D.S. Noyce and T. Vermeulen, The kinetics of aromatic nitration, Ind. Eng. Chem., 56 (1964) 43-53.

[25] J.M. Zaldivar, C. Barcons, H. Hernández, E. Molga and T.J. Snee, Modelling and optimization of semibatch toluene mononitration with mixed acid from performance and safety viewpoints, Chem. Eng. Sci., 47 (1992) 2517-2522.

[26] P.R. Cox and A.N. Strachan, Two phase nitration of toluene I, Chem. Eng. Sci., 27 (1972) 457-463.

[27] J.W. Barnet, R.B. Moodie, K. Schofield and J.B. Weston, Electrophilic aromatic substitution. Part XIII. Kinetics, isomer yields and the consequences of ipso-attack in the nitration of toluene and polymethylbenzenes in aqueous sulphuric acid, and their significance for the mechanism of aromatic nitration, J. Chem. Soc., Perkin Trans. 2 (1975) 648-654.

[28] R.G. Coombes, D.H.G. Crout, J.G. Hoggett, R.B. Moodie and K. Schofield, Electrophilic aromatic substitution. Part VI. Kinetics and mechanism of nitration of halogenobenzenes, $J$. Chem. Soc. $B(1970) 347-357$.

[29] N.C. Deno, H.J. Peterson and E. Sacher, Nitric acid equilibria in water-sulphuric acid, J. Phys. Chem., 65 (1961) 199-201.

[30] N.C. Marziano, P.G. Traverso, A. de Santis and M. Sampoli, Determination of the basicity of nitric acid in concentrated sulphuric acid by Raman and ultraviolet spectroscopy, J. Chem. Soc., Chem. Commun., 20 (1978) 873-874.

[31] M. Sampoli, A. De Santis and N.C. Marziano, On the relationship between the dissociation of indicators in non-ideal acid solution and the dissociation of the acid itself, J. Chem. Soc., Chem. Commun. (1985) 110-111.

[32] D.S. Ross, K.F. Kuhlmann and R. Malhotra, Studies in aromatic nitration $2 .{ }^{14} \mathrm{~N}$ NMR study of the nitric acid/nitronium ion equilibrium in aqueous sulphuric acid, J. ACS, 105 (1983) $4299-4302$. 
[33] N.C. Marziano, C. Tortato and M. Sampoli, Thermodynamic nitration rates of aromatic compounds. Part 3. Nitration of aromatic compounds in concentrated aqueous trifluoromethanesulphonic acid, J. Chem. Soc., Perkin Trans., 2 (1991) 423-429.

[34] N.C. Marziano, G.M. Cimino and R.C. Passerini, The $M_{c}$ activity coefficient function for acid-base equilibria. Part I. New methods for estimating $\mathrm{pKa}$ values for weak bases, J. Chem. Soc., Perkin Trans. 2 (1973) 1915-1922.

[35] N.C. Marziano, A. Tomasin, and P.G. Traverso, The $M_{c}$ activity coefficient function for acid-base equilibria. Part 5. The $M_{\mathrm{c}}$ activity coefficient for reliable estimate of thermodynamic values, J. Chem. Soc., Perkin Trans. 2 (1981) 1070-1075

[36] M. Sampoli, A. De Santis, N.C. Marziano, F. Pinna and A. Zingales, Equilibria of nitric acid in sulfuric and perchloric acid at $25^{\circ} \mathrm{C}$ by Raman and UV spectroscopy, J. Phys. Chem., 89 (1985) $2864-2869$.

[37] R.A. Cox, M.F. Goldman and K. Yates, The hydrolyses of some sterically crowed benzoate esters in sulfuric acid. The excess acidity method at different temperatures, Can. J. Chem., 57 (1979) $2960-2966$.

[38] E.B. Robertson and H.B. Dunford, The state of the proton in aqueous sulfuric acid, J. ACS, 86 (1964) $5080-5089$

[39] N.C. Marziano, personal communication,

[40] Cerfontain, 1965.

[41] H.A.M. Ismail, Ph.D. Thesis, University of Bradford, UK, 1973.

[42] N.C. Deno and C. Perizzolo, The application of activity coefficient data to the relations between kinetics and acidity functions, J. ACS, 79 (1957) 1345 1348.

[43] Cerfontain and Telder, 1965.

[44] J.W. Chapman and A.N. Strachan, Two phase nitration of chlorobenzene in $79.8^{\circ} \%$ sulfuric acid, in L.F. Albright and C. Hanson (eds.). Industrial and Laboratory Nitrations, ACS Symposium Series, 22, Washington, DC, 1976, pp. 219-223.

[45] A.J. Barduhm and K.A. Kobe, Toluene nitration kinetics, Ind. Eng. Chem.. 48 (1956) $1305-1315$

[45] L.R. Pcrkins and C.J. Geankoplis, Molccular diffusion in a ternary liquid system with the diffusing component dilute, Chem. Eng. Sci., 24 (1969) 1035-1042.

[46] J.W. Giles, Ph.D. Thesis, University of Bradford, UK, 1970.

[47] M. Sohrabi, Ph.D. Thesis, University of Bradford, UK, 1972.

[48] K.R. Westerterp, W.P.M. van Swaaij, and A.A.C.M. Beenackers. Chemical Reactor Design and Operation, Wiley, Chichester, 1984.

[49] M. Steensma and K.R. Westerterp, Thermally safe operation of a cooled semi-batch reactor. Slow liquid-liquid reactions, Chem. Eng. Sci., 43 (1988) 2125 - 2130.

[50] C. Hanson and H.A.M. Ismail, Diffusion of benzene and toluene into aqueous nitric acid-sulphuric acid mixtures, J. Appl. Chem. Biotechnol., 26 (1976) $111-116$.

[51] J.W. Chapman, P.R. Cox and A.N. Strachan, Two phase nitration of toluene III, Chem. Eng. Sci., 29 (1974) 1247-1251.

[52] J.B. Fernandes and M.M. Sharma, Effective interfacial area in agitated liquid-liquid contactors, Chem. Fng. Sri.. 22 (1967) $1267-1282$

[53] P.H. Calderbank and M.B. Moo-Young, The continuous phase heat and mass-transfer properties of dispersions, Chem. Eng. Sci. 16 (1961) 39-54.
[54] V.W. Uhl and J.B. Gray (eds.), Mixing: Theory and Practice, Vol. 2, Academic Press, New York, 1967.

[55] M. De Santiago and P. Trambouze, Applicabilité de la méthode chimique de mesure de l'aire interfaciale, Chem. Eng. Sci., 26 (1971) 1803-1815 (in French).

[56] J.R. Bourne, M. Buerli and W. Regenass, Heat transfer and power measurements in stirred tanks using heat flow calorimetry, Chem. Eng. Sci., 36 (1981) 347-354.

[57] G.F.P. Harris, Isomer control in the mononitration of toluene, in L.F. Albright and C. Hanson (eds.), Industrial and Laboratory Nitrations, ACS Symp. Series, 22, Washington, DC, 1976, pp. $300-312$

[58] J.M. Zaldivar, H. Hernández, C. Barcons and R. Nomen, Heat effects due to dilution during aromatic nitrations by mixed acid in batch conditions, J. Thermal Anal, 38 (1992) 2575-2582.

[59] J.M. Zaldivar, E. Molga, M.A. Alós, H. Hernández and K.R. Westerterp, Aromatic nitrations by mixed acid. Fast liquid-liquid reactions, submitted for publication in

[60] Liu and Grén, 1991.

[61] Kumar and Patwardhan, 1992

[62] D. Al-Khudhairy and J.M. Zaldivar, Activity coefficients in $\mathrm{HNO}_{3}-\mathrm{H}_{2} \mathrm{SO}_{4}-\mathrm{H}_{2} \mathrm{O}$ mixtures, Technical Note I.89.90, 1989 (Joint Research Centre, Ispra Site, Italy).

[63] E. Hàla, I. Wichterle, J. Polàk and T. Boublik, Vapour-Liquid Equilibrium Data at Normal Pressures, Pergamon Press, London, 1968.

[64] A. Bosen and H. Engels, Description of the phase equilibrium of sulfuric acid with the NRTL equation and a solvation model in a wide concentration and temperature range, Fluid Phase Equilibria. 43 (1988) 213-230.

[65] S. Fénéant and J. Chédin. Dosages par effet Raman et équilibres de formation de l'ion $\mathrm{NO}_{2}^{+}$dans les mèlanges binaires $\mathrm{HNO}_{3}$ $\mathrm{H}_{2} \mathrm{SO}_{4}$, Compt. Rendus, 243 (1956) $141-144$ (in French).

[66] G.B. Guarise, Attività nel sistema $\mathrm{HNO}_{3}-\mathrm{H}_{2} \mathrm{SO}_{4}-\mathrm{H}_{2} \mathrm{O}, \mathrm{La}$ Chimica e l'Industria, 48 (1966) 1316-1322 (in Italian).

[67] G.F. Sheats and $\Lambda . N$. Strachan, Rates and activation energies of nitronium ion formation and reaction in the nitration of toluene in $\sim 78 \%$ sulphuric acid, Can. J. Chem., 56 (1978) $1280-1283$.

[68] Perry and Chilton, 1984

[69] D. van Velzen, R. Lopes and H. Langenkamp, Liquid viscosity and chemical constitution of organic compounds: a new correlation and a compilation of literature data, EUR 4735e, 1972 (Joint Research Centre, Ispra Site, Italy).

[70] Ismail and Hanson, 1973.

[71] P.R. Cox and A.N. Strachan. Two-phase nitration of toluene, Part II, Chem. Eng. J., 4 (1972) 253-261.

[72] P.H. Calderbank, Mass transfer, in V.W. Uhl and J.B. Gray (eds.), Mixing Theory and Practice, Academic Press, New York, 1967.

[73] W.F. Giauque, E.W. Hornung, J.E. Kunzler and T.R. Rubin, The thermodynamic properties of aqueous solutions and hydrates from 15 to $300 \mathrm{~K}, J . A C S, 82$ (1960) 62-70.

[74] P.G. Traverso. N.C. Marziano and R.C. Passerini. The $M_{\mathrm{s}}$ activity coefficient function for acid-base equilibria. Part 4 . Limitations of empirical relationships involving observed nitration rates and acidity functions, J. Chem. Soc.. Perkin Trans. 2 (1977) 845-847 